\title{
Simulation of Effect of Force Chain on Graphite Migration of Copper Based Graphite Composites During Friction
}

\section{Kun Chen}

Hefei University of Technology

Ting Xie ( $\nabla$ txie@hfut.edu.cn )

Hefei University of Technology https://orcid.org/0000-0003-3148-8814

Longxiao Zhang

Hefei University of Technology

Chen Li

Hefei University of Technology

\section{Heng Wen}

Hefei University of Technology

\section{Xiang Meng}

Hefei University of Technology

\section{Research Article}

Keywords: Numerical simulation, Copper based graphite composite, Force chain, Migrated graphite particle

Posted Date: May 21st, 2021

DOI: https://doi.org/10.21203/rs.3.rs-409881/v1

License: (9) This work is licensed under a Creative Commons Attribution 4.0 International License. Read Full License 


\title{
Simulation of effect of force chain on graphite migration of copper based graphite composites during friction
}

\author{
Kun Chen, Ting Xie*, Longxiao Zhang, Chen Li, Heng Wen, Xiang Meng \\ Institute of Tribology \\ School of Mechanical Engineering \\ Hefei University of Technology \\ Hefei, 230009, China
}

\begin{abstract}
To further reveal the mechanism of graphite migration in copper based graphite composites sliding against 45 steel, the particle Flow Code in 2 Dimensions (PFC2D) was employed to simulate and analysis the relationship between internal force chain and graphite migration in the composites. The simulation results show that a migrated graphite particle layer is formed on the composite surface during friction, and maintains dynamic equilibrium relying on "self-consumption". The graphite migration displacement to the friction surface is affected by the force chain. The greater the force chain strength is, the smaller the graphite migration displacement is. When the force chain angle is in the range of $75^{\circ}$ to $95^{\circ}$, the migration of the graphite particles can not occur; when the angle is $95^{\circ}$ to $135^{\circ}$, the graphite migration displacement increases with the increase of the angle. And the greater force chain strength corresponds to the less worn particles and the less migrated graphite particles. The simulation results are significant for optimizing material design and improving the friction performances of copper based graphite composites.
\end{abstract}

\section{Keywords}

Numerical simulation, Copper based graphite composite, Force chain, Migrated graphite particle.

\section{Corresponding author}

Ting Xie

Hefei University of Technology

193 Tunxi Road

Hefei, Anhui, China, 230009

Phone: (86) 0551-62901121

Email: txie@hfut.edu.cn

\section{Ethics declarations}

Conflict of interest:

The authors declare that they have no conflicts of interest. 


\section{Introduction}

Copper based graphite composites have excellent mechanical properties, antioxidation, anticorrosion, antifriction and antiwear properties, which favor them various applications in sliding bearing, shaft sleeve, electric contact, high speed rail pantograph and a large number of friction pair parts [1-6]. The key performance of copper based graphite $(\mathrm{Gr} / \mathrm{Cu})$ composites is their self-lubricating properties, therefore, the research on their self-lubricating properties has always been the focus of attention. Zhan et al. [7] studied the $(\mathrm{SiC}+\mathrm{Gr}) / \mathrm{Cu}$ composites antifriction mechanism, and revealed that a graphite rich tribolayer formed on the worn surface was responsible for good tribological properties of the composites. Xu et al. [8] prepared copper based graphite composites by powder metallurgical method, large size cluster graphite as solid lubricant was added into the matrix to optimize the mechanical and wear performance of the composites. Liu et al. [9] showed when aluminium-graphite composites sliding against steel, due to the precipitation of graphite particles, forming a lubrication film on both the tribosurfaces of the composites sample and the steel counterface, leaded to the reduction in friction and wear. Rohatgi et al. [10] found when graphite solid lubricants were added to metal matrix, the metal matrix surface form a relatively stable lubrication film during friction extrusion and thermal action, and the solid lubricant can be constantly supplied and provided by "self-consumption".

The dynamic behavior of graphite and the lubrication film formation mechanism of the copper based composites are difficult to observe and record in friction process by experimental methods. Up to now, the dynamic migrating process of graphite from matrix to surface to form lubrication film is not clear, which is very important to understand the antifriction mechanism of copper based graphite composites. Therefore, it is necessary to find a numerical simulation method to solve this problem. At present, the simulation of friction process has become a research hotspot. Different methods have been employed to simulate the friction and wear process of materials. The microscale frictional behavior and wear processes of four sealing materials are 
simulated through a numerical method based on the movable cellular automata (MCA) [11]. Liu et al. [12] employed fluent software to calculate the aluminum alloy spool valve body material wear prediction model. Qin et al. [13] presents a numerical simulation of a lubricated fretting contact using a Coupled-Eulerian-Lagrangian (CEL) finite element method. Schulze et al. [14] based on a technological approach and Fick's second law establish a simulation model to numerical description of the carburizing process for graded porous PM-components. A three-dimensional finite element model was established to simulate the failure process of self-lubricating spherical plain bearings in the swinging wear condition [15]. A multi-scale method based on coupling the finite element method (FEM) and DEM is used to model the shear process of two parallel plates with solid particles between them [16]. Zhang et al. [17] researched binary system powders by the discrete element method. Xie et al. $[18,19]$ studied the dynamic evolution of the PTFE/45 steel friction pair friction interface, and analyzed the friction transfer of PTFE.

Each method has its own characteristics. Considering the advantages of DEM in studying the particle motion and propagation of cracks and fracture, which closely relate to the friction and wear process, in our work, a DEM software "the Particle Flow Code in 2 Dimensions" (PFC2D) was employed to simulate the dynamic process of graphite migration of copper based graphite composites/45 steel friction pair, to reproduce force chain change and graphite migration in the composites friction and wear process at the micro level. The research results have theoretical significance and practical guiding significance for optimize the composites design and their tribological properties.

\section{Numerical simulation}

\subsection{Model of the friction pairs and the micro-parameters}

In this study, the PFC2D software is used to build the particle flow friction system [20, 21]. In the numerical model, copper based graphite composites and 45 steel were 
selected as friction pairs. The contact model was parallel bonding model, the particle size was uniformly distributed, the rigid wall was used as the boundary, the composites was generated by the radius enlargement method. The lower sample of $\mathrm{Gr} / \mathrm{Cu}$ composites (length $2.5 \mathrm{~mm}$ and width $1.2 \mathrm{~mm}$ ) is composed of 3818 copper particles with a radius of $15 \mu \mathrm{m}$ and 9152 graphite particles with a radius of $3.0 \mu \mathrm{m}$, and the upper sample of 45 steel is composed of 88 particles with radius of $0.1 \mathrm{~mm}$ arranged in a circle of radius $1.5 \mathrm{~mm}$, and it is assumed that 45 steel will not be worn. A vertical upward load is applied on the bottom boundary of the copper based graphite composites, the load is $8 \mathrm{MPa}$. The lower sample is fixed and the upper sample moves in a rotation motion with speed of $0.2 \mathrm{~m} / \mathrm{s}$, and establish coordinate system (as shown in Fig. 1).

In this work, the PFC2D software is used to establish the mathematical model of the friction system, and the computational model and method similar to our previous work $[18,19,22]$. The flow chart of the simulation process by PFC2D is shown in Fig. 2.

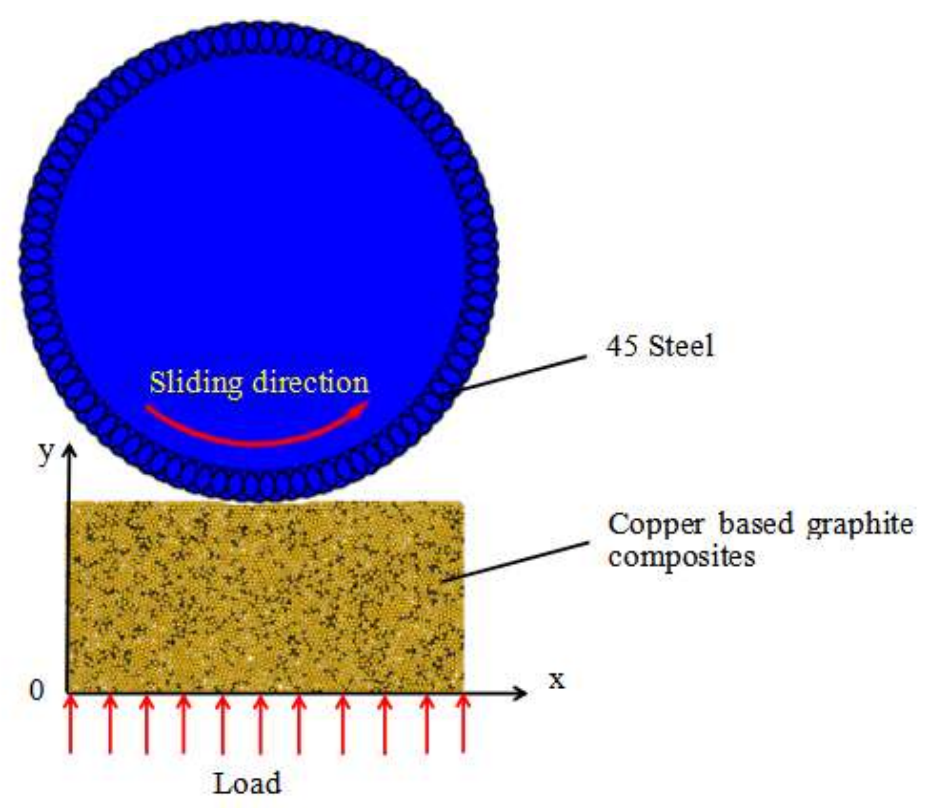

Fig. 1 Numerical simulation model of the friction pair 


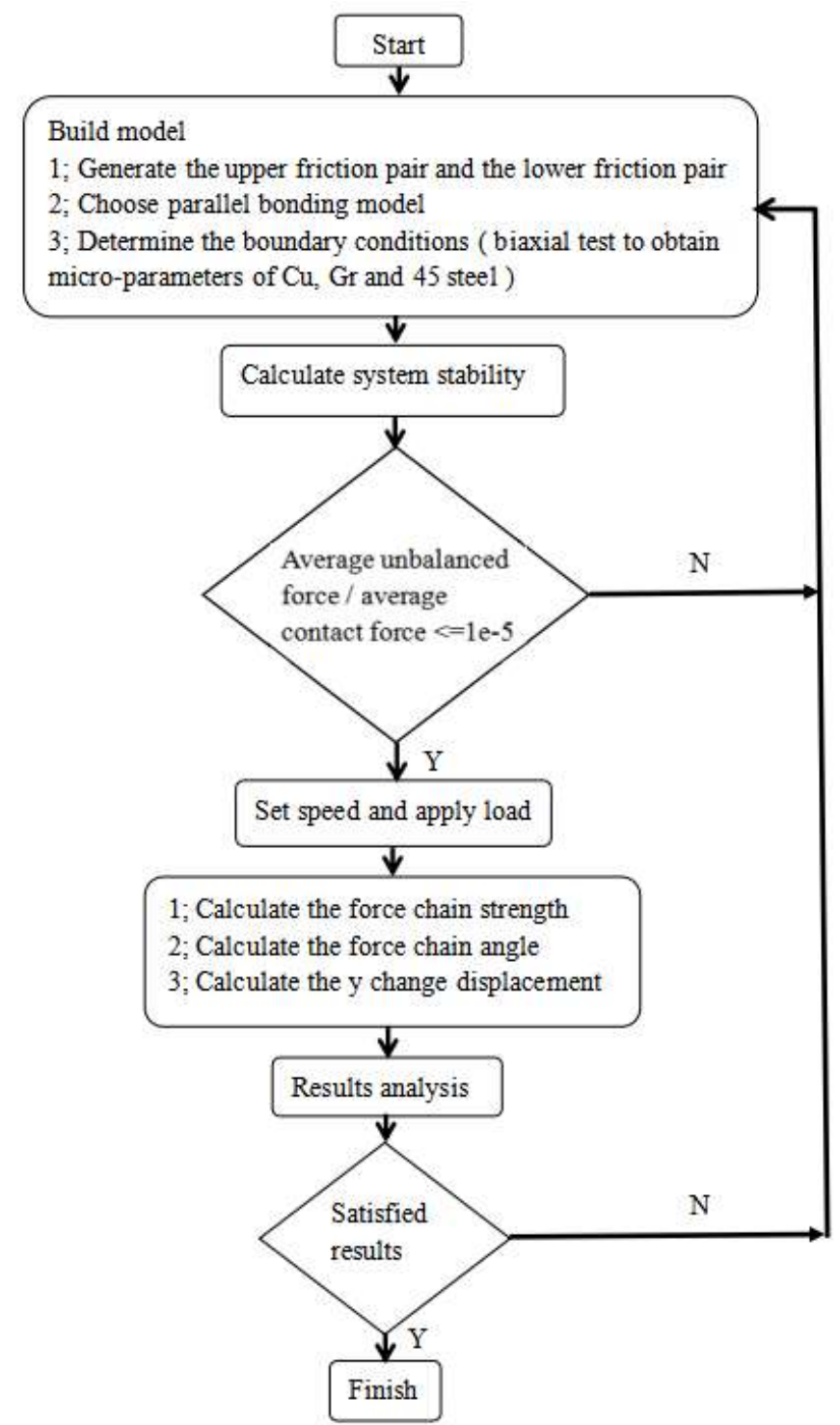

Fig. 2 Flow chart of the simulation process by PFC2D

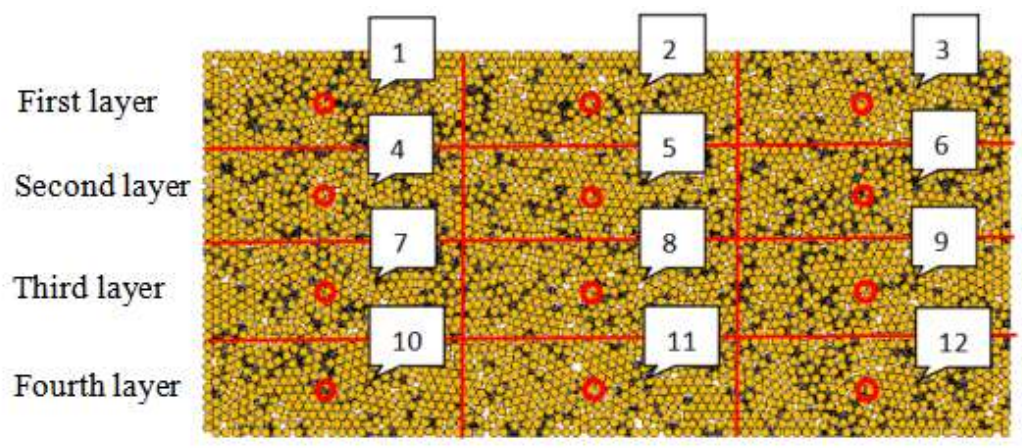

Fig. 3 Selected target particles

In order to conveniently studying the motion law of particles in different representative positions, selected some graphite particles in fixed positions within the 
matrix, and their motion paths are tracked and recorded. Because the particle force is related to the friction surface distance, so the matrix from the friction contact surface to the bottom is divided into four layers, and considering the effect of the distance of the particle to the contact area, from left to right is three columns. Each layer width is $0.625 \mathrm{~mm}$, and each column width is $0.4 \mathrm{~mm}$. A selected graphite particle in each area is numbered from 1 to 12 , respectively (see Fig. 3).

Biaxial test was employed to obtained the micro-parameters in this simulation.

The determined micro-parameters of the model are shown in Table 1.

Table 1 Micro-parameters of $\mathrm{Cu}, \mathrm{Gr}$ and 45 steel

\begin{tabular}{lccc}
\hline \multicolumn{1}{c}{ Parameter } & $\mathrm{Cu}$ & $\mathrm{Gr}$ & 45 steel \\
\hline Density $/\left(\mathrm{kg} \cdot \mathrm{m}^{-3}\right)$ & 8700 & 2200 & 7800 \\
Particle radius $(\mathrm{m})$ & $15 \mathrm{e}-6$ & $3.0 \mathrm{e}-6$ & $0.75 \mathrm{e}-3$ \\
Friction coefficient & 0.2 & 0.1 & 0.36 \\
Effective modulus $(\mathrm{Pa})$ & $100 \mathrm{e} 9$ & $15 \mathrm{e} 9$ & $200 \mathrm{e} 9$ \\
Normal-to-shear stiffness ratio & 2.1 & 1.56 & \\
Bond effective modulus $(\mathrm{Pa})$ & $100 \mathrm{e} 9$ & $15 \mathrm{e} 9$ & \\
Bond normal-to-shear stiffness & 2.1 & 1.56 & \\
ratio & 200 & 54 & \\
Tensile strength $(\mathrm{MPa})$ & 160 & 40 & \\
Cohesion $(\mathrm{MPa})$ & 12 & 6 & \\
Friction angle $\left(^{\circ}\right)$ & &
\end{tabular}

\subsection{Some definitions}

\subsubsection{Force chain}

In order to extract the force chain information from numerical simulation model. In this paper defines three necessary conditions for a force chain: (1)The contact force must be greater than the average contact force in the system; (2)The angle between adjacent contacts must be greater than or equal to the angle threshold, which is obtained by $180^{\circ}$ dividing the system average coordination number; (3)The number of particles composing the force chain must be greater than or equal to 3 [23]. To quantify the influence of force chain on graphite migration, the force chain strength and force chain direction are defined as follows [24, 25]. 
Force chain strength $P_{i}$

$$
P_{i}=\frac{\sum_{k=1}^{s} f_{k}}{\sum_{j=1}^{s} d_{j, j+1}}
$$

Where $\sum_{k=1}^{s} f_{k}$ is the sum of the $s$ contact force of the ith force chain, $\sum_{j=1}^{s} d_{j, j+1}$ is sum of the distance between the $j$ and the $j+1$ particle centers of the ith force chain. In our work, the average force chain strength is the sum of force chain strength divided by the number of force chain in the region.

The force chain direction is the connection between the center of the head and tail particle (see Fig. 4). Where $\theta$ is force chain angle.

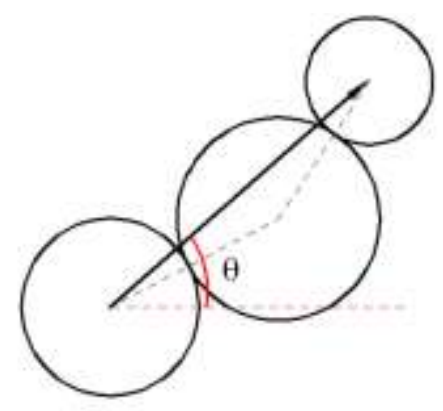

Fig. 4 Force chain direction

\subsubsection{Migration particle and worn particle}

During friction, under the actions of extrusion force and normal pressure, graphite is extruded from the body, and friction interface partial particles fall off from the body. Under certain conditions, some graphite particles establish new bonds with matrix, and attached to matrix surface to form a layer of particles, which are defined as migration particles (once they become migration particles, the particles will marked red to distinguish from the others). The other particles, which do not connect with matrix and the 45 steel surface will be discharged as the "debris" from the friction 
interface. The worn particles include two aspects: (1) migration particles; (2)"debris" particles.

3 Simulation results and analysis

\subsection{Basic evolution process of the friction interface}

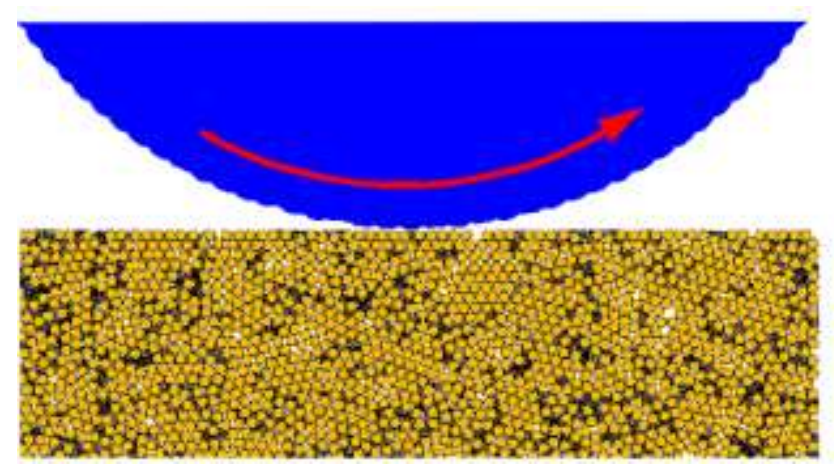

(a)

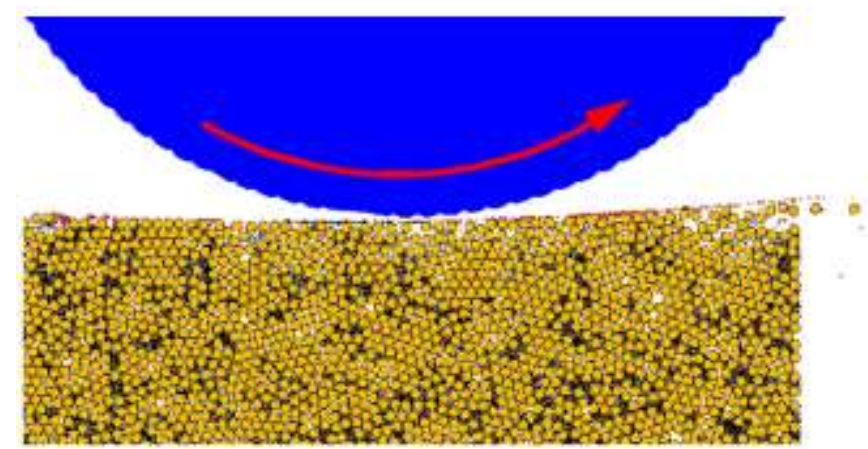

(b)

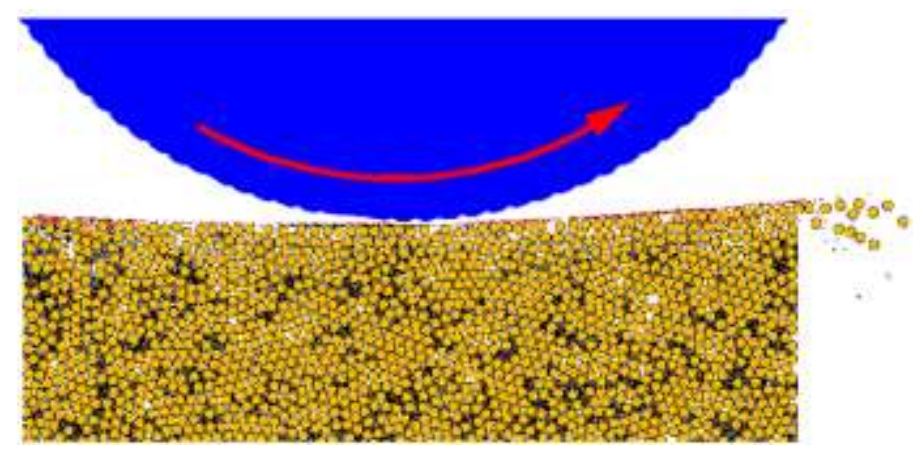

(c)

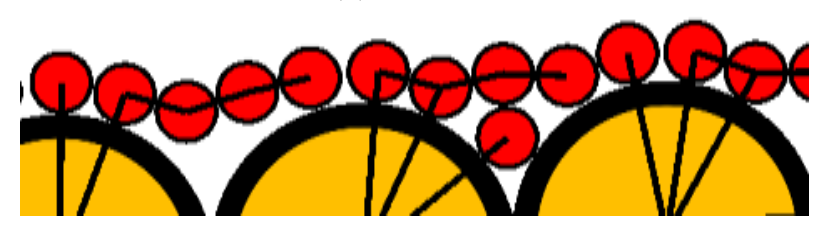

(d) 
Fig. 5 Particle migration and wear process at different time step, (a) time step 0; (b) time step 2500000; (c) time step 5000000; (d) Partially enlarged image of the migrated particle layer

Fig. 5 is the simulation results of the friction process of copper based graphite composites/45 steel. It can be clearly seen that the part close to the friction interface of the lower sample occurs elastic-plastic deformation under the action of sliding friction shearing force. With the progress of friction, the migration to matrix surface graphite particles will increase with the increase of time step, and the wear particles will also increase. This is mainly because the tangential and normal forces exceed the tangential and normal bonding strength between particles, the bonds between particles break, which results in weakly contact bonds graphite particles are extruded from the body, and partial graphite particles falling off from friction interface. Some of the particles will establish new bonds with the surface particles of the composites and adsorbed on the composites to form a migrated graphite particle layer (Fig. 5(d)). The formation and stability of the migrated particle layer makes the friction transition from fast wear to steady wear. The migrated particle layer has two functions: On the one hand, it protects the surface of the composites and reduces scratch by metal surface. On the other hand, as a lubricant, it reduces friction coefficient and wear. The experimental results proved that graphite particles are extruded from the metal matrix inside and adhered to the friction surface to forming a thin lubricating film, which tended to stabilize during steady state sliding [9, 26, 27].

\subsection{Evolution law of force chain}

Fig. 6 shows distribution of the force chain during friction, the thickness of the line is directly proportional to the force chain contact force. As indicated in Fig. 6, at the beginning of friction, the force chain is uniformly distribution throughout the matrix. With the progress of friction, the force chain is broken, and the maximum break occurs below the friction contact area, and force chain break gradually decreases to 
the sides and to depth. That's because the stress below the contact area is greater, and the bonds between particles break is larger, and the force chain crack is greater.

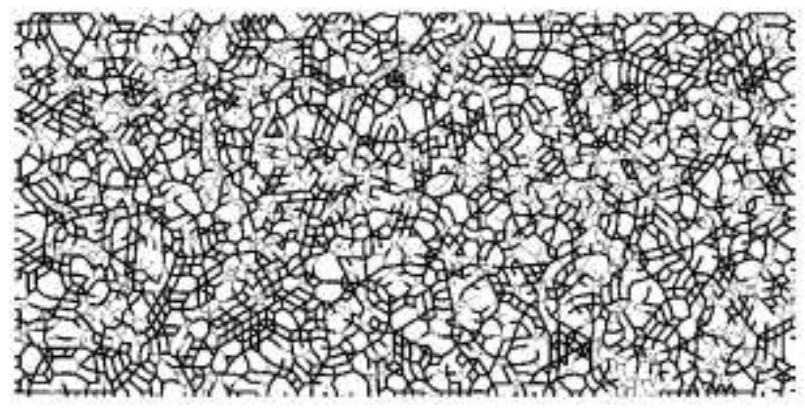

(a)

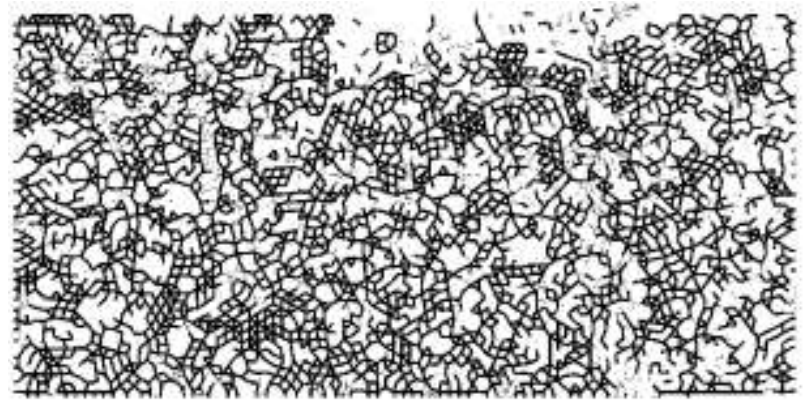

(b)

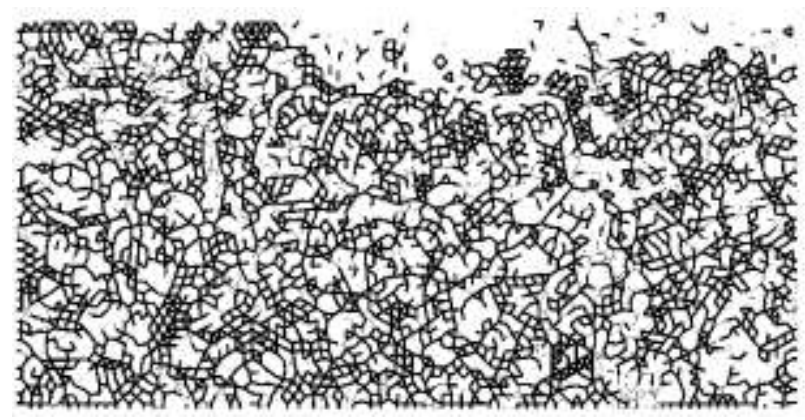

(c)

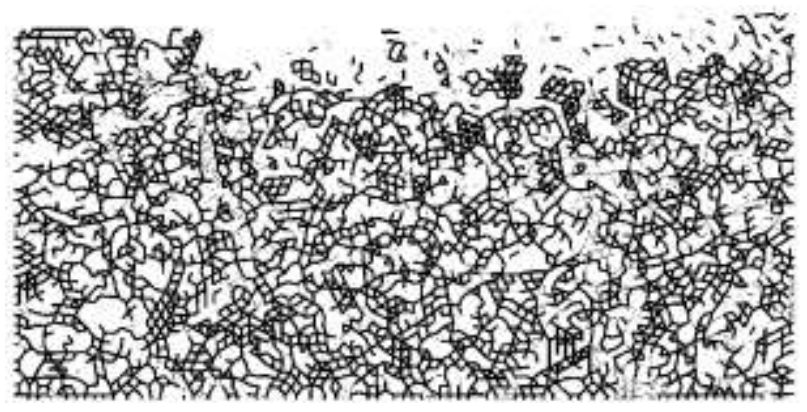

(d)

Fig. 6 Macroscopic distribution characteristics of the force chain, (a) time step 0; (b) time step 1500000; (c) time step 30000000; (d ) time step 4500000 


\subsection{Analysis of graphite migration dynamic process}

\subsubsection{Relationship between graphite migration and force chain strength}

The graphite migration to the friction surface, mainly observed the longitudinal graphite migration depth, so the y direction movement is more representative, that's y change displacement is called the migration displacement.

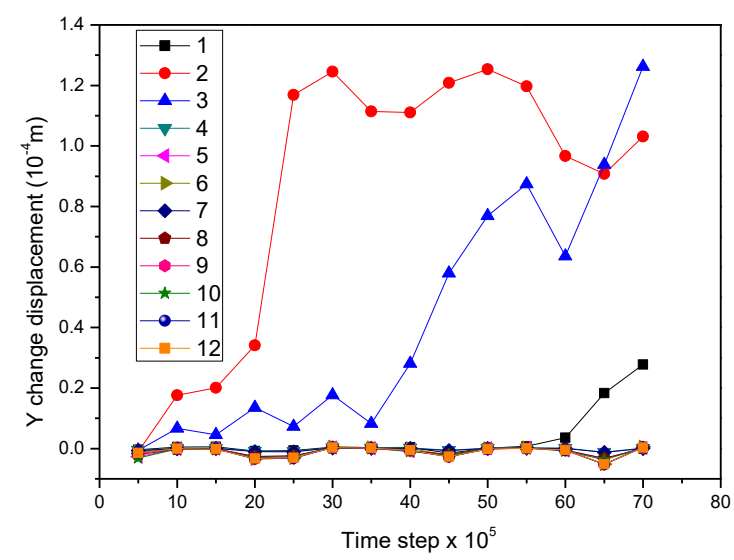

Fig. 7 Y migration displacement of the selected graphite particles

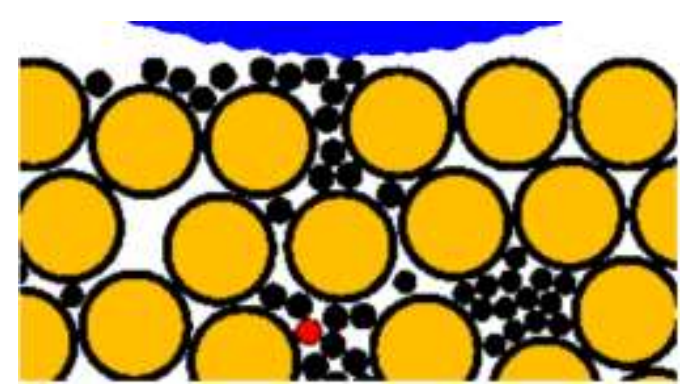

(a)

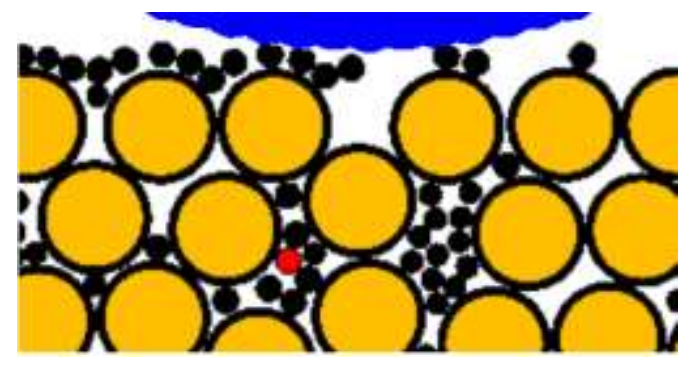

(b) 


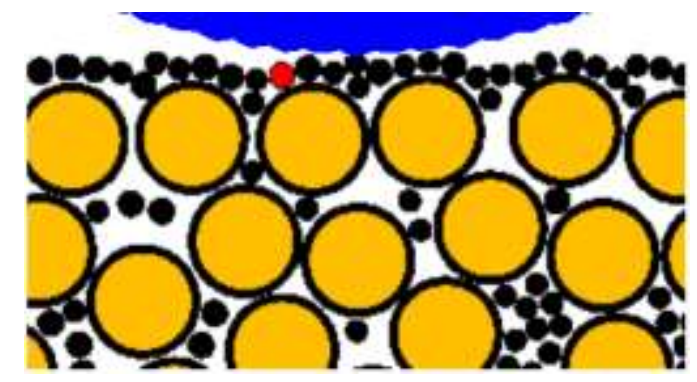

(c)

Fig. 8 Graphite particle 2 position state at different time step (the red particle is the target graphite particle 2), (a) time step 500000; (b) time step 2000000; (c)time step 3500000

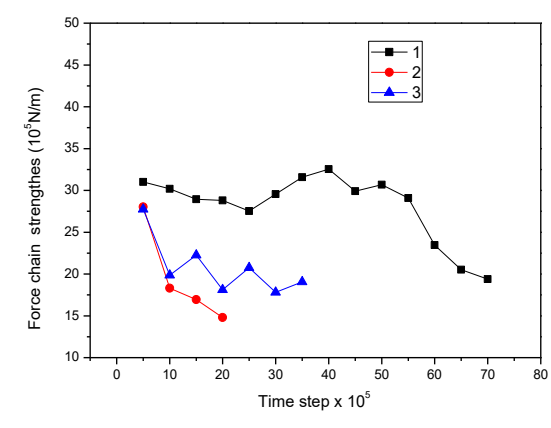

(a)

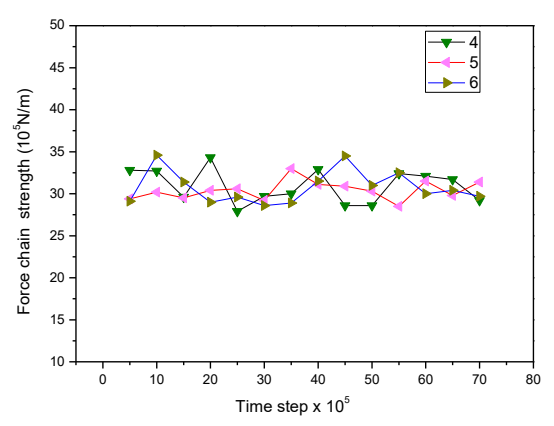

(c)

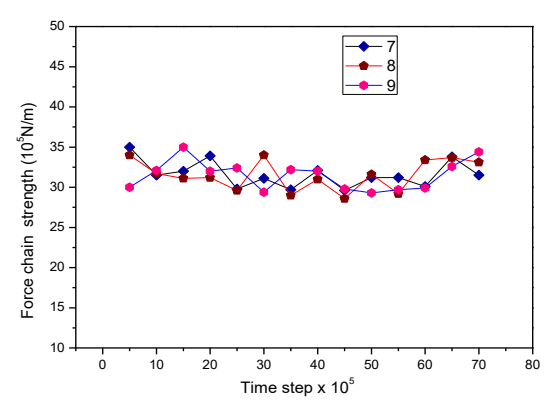

(e)

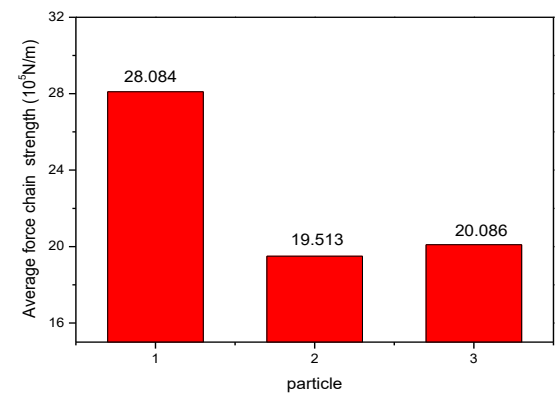

(b)

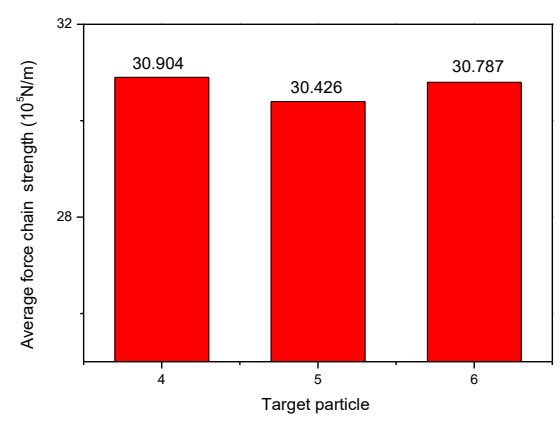

(d)

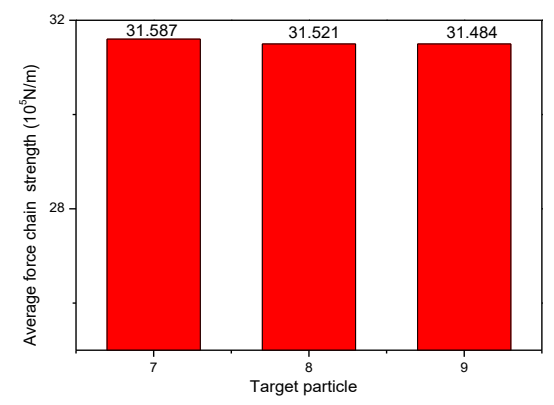

(f) 


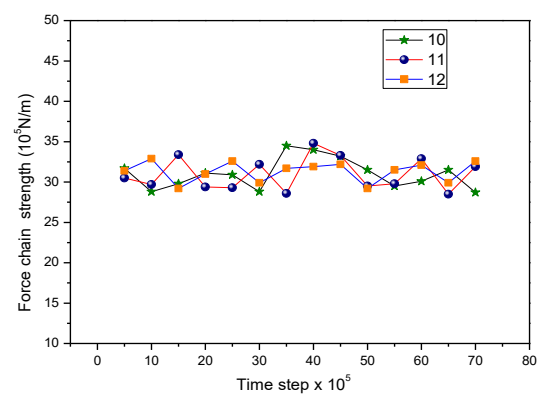

(g)

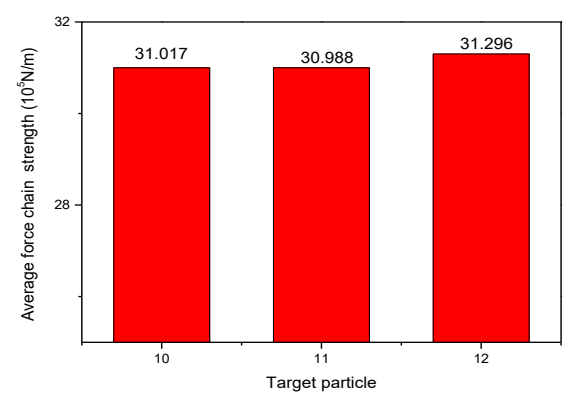

(h)

Fig. 9 Force chain strength at different time step, (a) Graphite particle 1 to 3 force chain strength vs time step; (b) Graphite particle 1 to 3 average force chain strength; (c) Graphite particle 4 to 6 force chain strength vs. time step; (d) Graphite particle 4 to 6 average force chain strength; (e) Graphite particle 7 to 9 force chain strength vs. time step; (f ) Graphite particle 7 to 9 average force chain strength; (g) Graphite particle 10 to 12 force chain strength vs. time step; (h) Graphite particle 10 to 12 average force chain strength

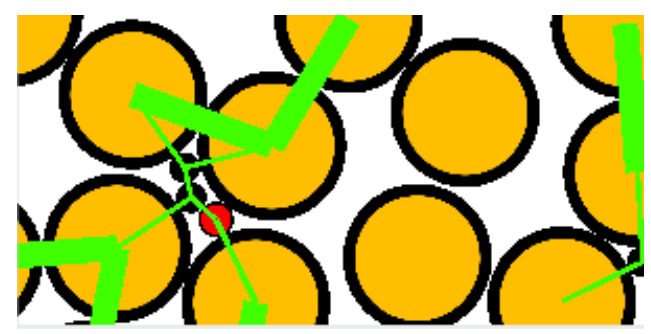

(a)

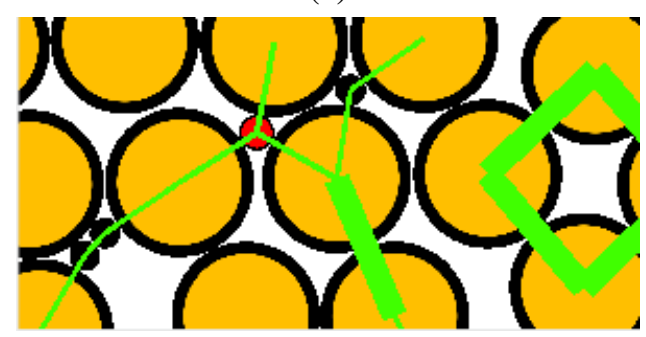

(b)

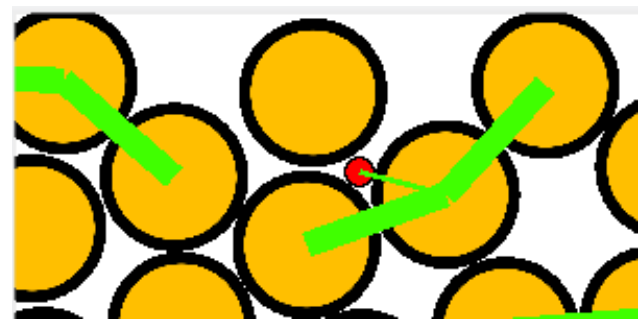

(c)

Fig. 10 Graphite particle 3 force chain state at different time step (the red particle is the target graphite particle 3), (a) time step 1000000; (b) time step 2000000; (c) time step 3000000 


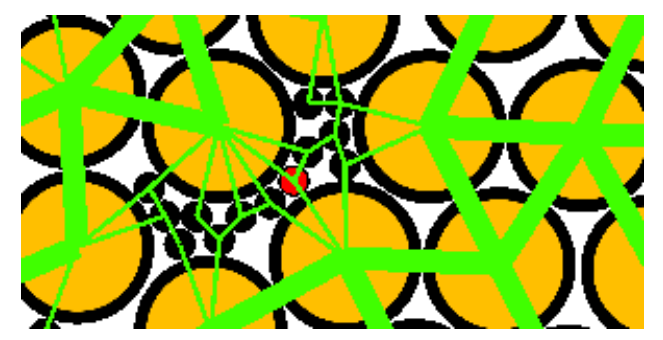

(a)

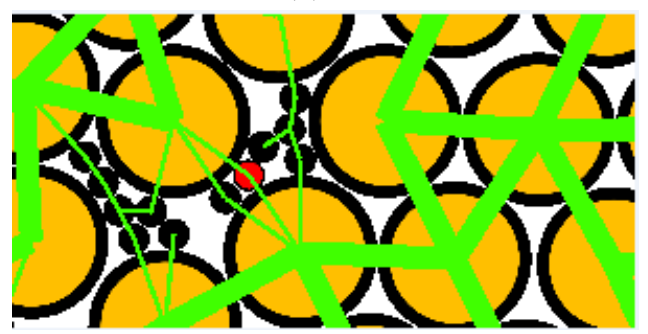

(b)

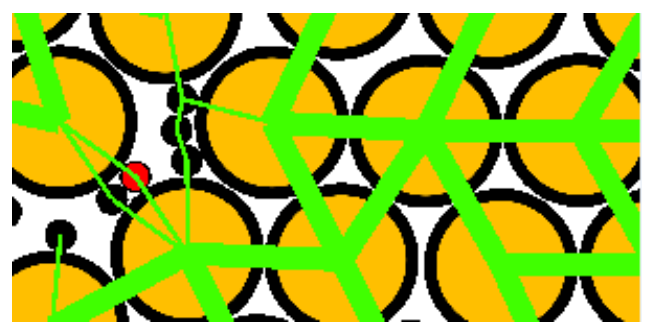

(c)

Fig. 11 Graphite particle 5 force chain state at different time step (the red particle is the target graphite particle 5), (a) time step 2000000; (b) time step 4000000; (c)time step 6000000

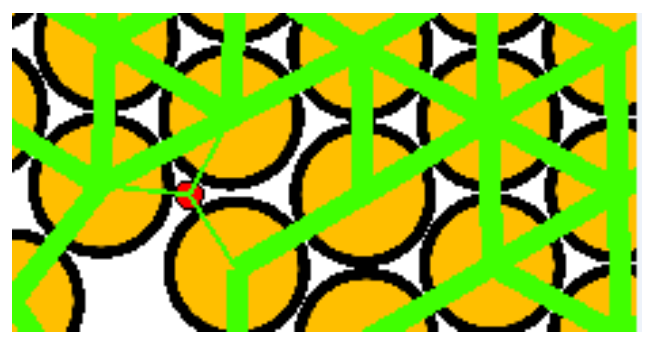

(a)

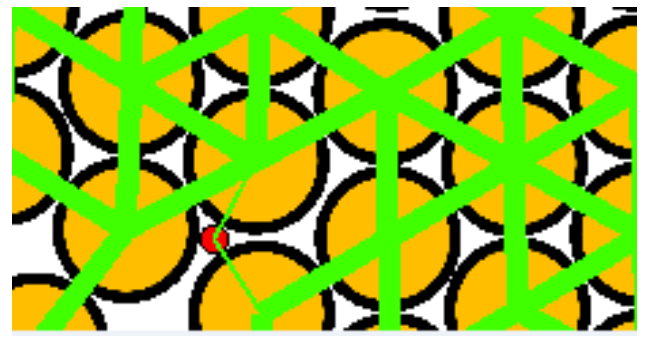

(b) 


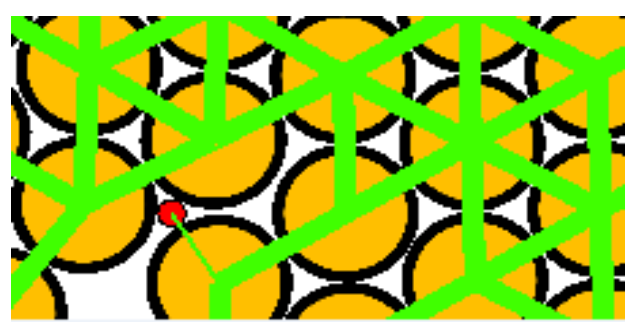

(c)

Fig. 12 Graphite particle 8 force chain state at different time step (the red particle is the target graphite particle 8), (a) time step 2000000; (b) time step 4000000; (c)time step 6000000

Fig. 7 shows the y migration displacement of selected 12 graphite particles. Fig. 7 illustrates that the graphite particles migration mainly occurs in the first layer within 7000000 time step, and graphite particles 1, 2 and 3 have obvious migration displacement. But the other graphite particles change displacement are not obvious.

Because the graphite particles in different layer have different stress states. Therefore, the force chain strength of each layer is calculated separately. Fig. 9 shows the force chain strength of graphite particles 1 to 12 at different time step, and the average force chain strength within 7000000 time step. As indicated in Fig. 7 and Fig. 8 , the force chain strength of the graphite particle 2 from $2750000 \mathrm{~N} / \mathrm{m}$ to $1300000 \mathrm{~N} / \mathrm{m}$ and the force chain strength of the graphite particle 3 from $2700000 \mathrm{~N} / \mathrm{m}$ to $1800000 \mathrm{~N} / \mathrm{m}$ during the 0 to 2000000 time step, respectively. At this time, the migration displacement of the graphite particle 2 is $0.000026 \mathrm{~m}$ and the graphite particle 3 is $0.000012 \mathrm{~m}$, respectively. This is because the force chain destroy gradually decreases towards the depth and both sides of the contact area during friction, the stronger force chain pushes the particles of the weaker force chain move to weaker force chain direction, and within a certain time step the smaller the force chain strength is, the greater the graphite migration displacement is. During friction, the force chain strength changes in different area, and the migration displacement of graphite particles also changes. At the time step 2000000, the graphite particle 2 is not affected by the force chain, so the migration displacement sharply increased. During the 2500000 to 5500000 time step the graphite particles 2 as migration particle, and migration displacement remains almost constant. At the time step 5500000 the graphite particle 2 becomes "debris". The graphite particle 3 force chain strength 
decreases, and migration displacement increases during the 0 to 3500000 time step. At the time step 3500000 the graphite particle 3 is not affected by the force chain, and fast migration to the friction surface. At the time step 5500000 the graphite particle 3 is expelled as "debris". The graphite particle 1 force chain strength decreases, and begins to produce obvious migration displacement at the time step 5500000 .

Fig. 9 (c)-(h) show graphite particles 4 to 12 the force chain strength fluctuates within a certain range, and average force chain strength does not differ much. Because the force chain is stable, these particles did not produce obvious migration displacement. Fig. 11 and Fig. 12 show force chain state of graphite particle 5 and graphite particle 8 at different time step, respectively. It can be clearly seen that the force chain remain stable at this layer.

The research results showed that graphite particles migration is related to the force chain break. That is, the greater the force chain strength is, the smaller the graphite migration displacement is, and the direction of particle movement is the direction of strong force chain to weak force chain.

\subsubsection{Relation between graphite migration displacement and force chain angle}

Fig. 13 shows the relationship between graphite particles migration displacement and force chain angle. As indicated in Fig. 13, when the force chain angle is 750 to 95o, the particles are stable and no migration displacement occurs. The migration displacement increases with the angle increase when the force chain angle is in the range of $95^{\circ}$ to $135^{\circ}$. This is mainly due to the force chain strength is strong at angle is $75^{\circ}$ to $95^{\circ}$, as the angle increase, force chain strength reduce lead to particles move. Fig. 14 is relations between force chain strength and force chain angle. 


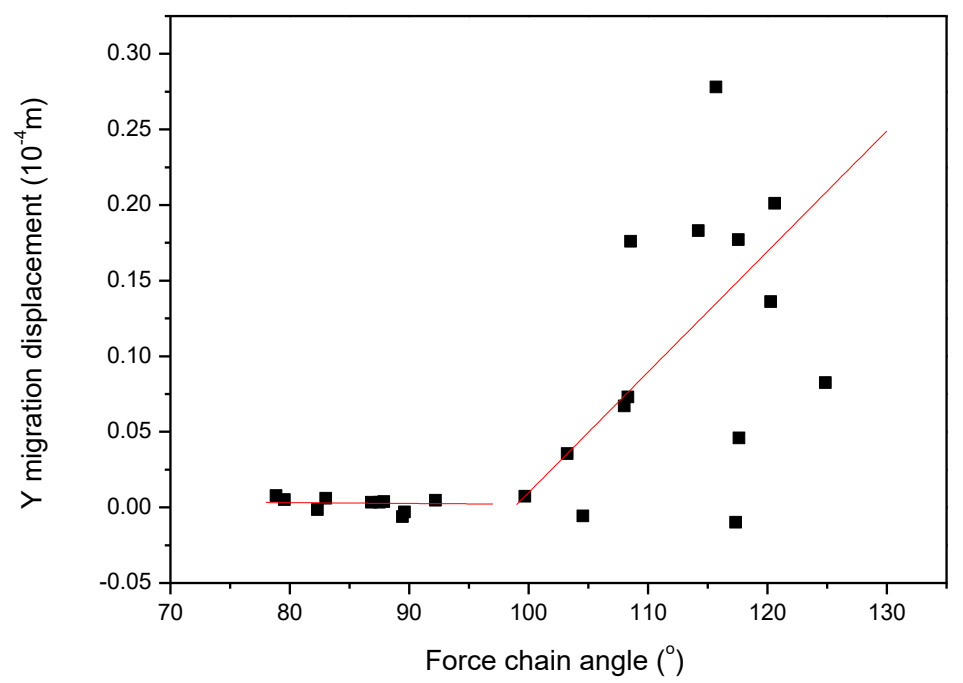

Fig. 13 Relations between graphite migration displacement and force chain angle

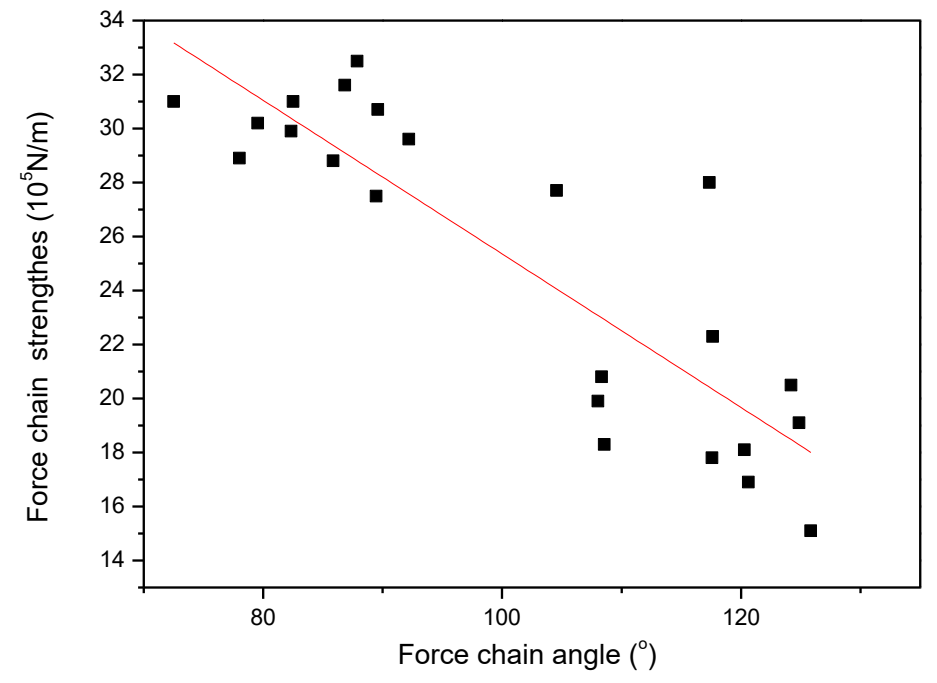

Fig. 14 Relations between force chain strength and force chain angle

\subsection{Effect of force chain strength on the migration particle numbers and the} worn particle numbers

Fig. 15(a) and (b) show the relations of migration particle numbers with force chain strength and worn particle numbers with force chain strength, respectively. As indicated in Fig. 15, the greater force chain strength corresponds to the less worn 
particles and the less migrated graphite particles. This is because the increase of force chain strength leads to the increase of the particles bonds, the ability of particles move to the friction interface is weakened, thus resulting in the reduction of the worn particles and the migration particles.

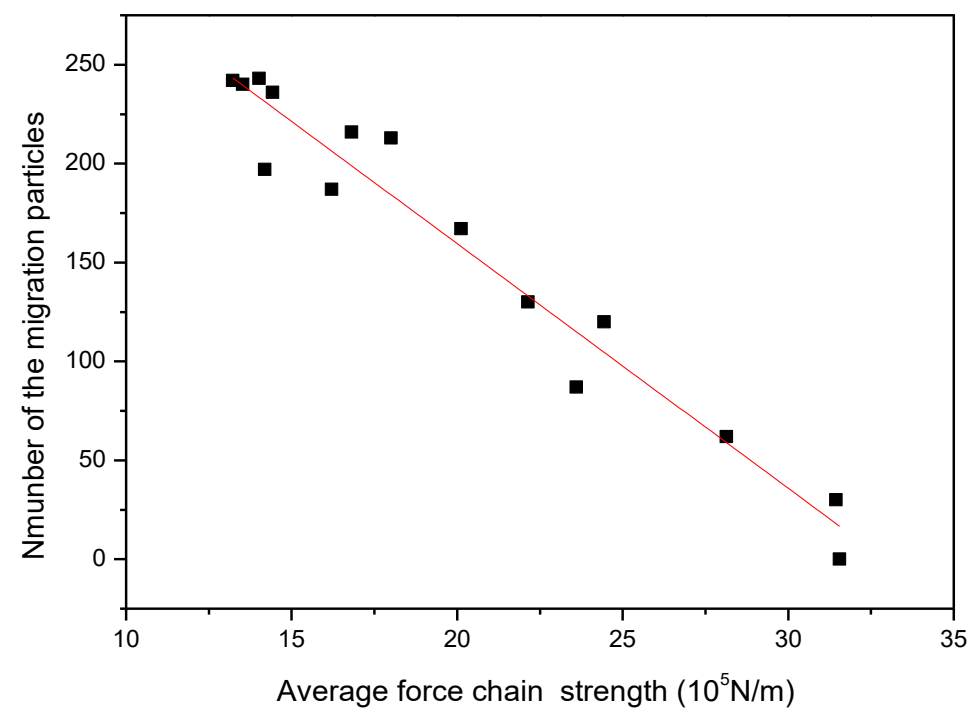

(a)

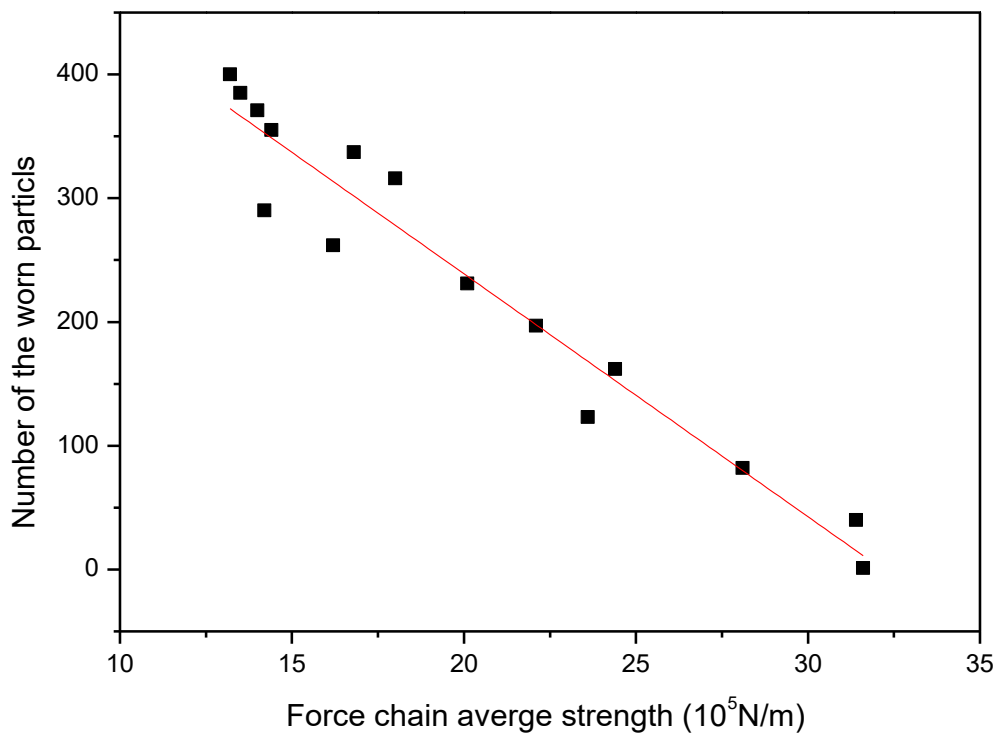

(b)

Fig. 15 Relations of the migration particle with average force chain strength (a) and the worn particle with average force chain strength (b) 
The simulation results showed that the particle motion is not only affected by the surrounding particles, but also affected by farther away particles through the force chain. It is important to explore the evolution of the internal force chains in the friction system on copper based graphite composites, because it has a great significance in the research on how to improve the tribological performance of the composites.

\section{Conclusion}

The mechanism of graphite migration and the formation of a migrated graphite particle layer was successfully simulated by using PFC2D software. The effect of $t$ force chain was considered in the simulation, which is rarely reported before. It is helpful for us to understand the formation of lubrication film and for the control of the wear process.

The following conclusions were drawn from our simulation results:

(1) After a certain time step, a relatively stable migrated graphite particle layer is formed on matrix surface, and maintain dynamic equilibrium of graphite relying on "self-consumption".

(2) During friction, the migration displacement of graphite particles in the matrix to the friction surface were affected by the force chain. The greater the force chain strength is, the smaller the graphite migration displacement is. When the force chain angle is in the range of $75^{\circ}$ to $95^{\circ}$, the migration of the graphite particles can not occur; when the angle is $95^{\circ}$ to $135^{\circ}$, the graphite migration displacement increases with the increase of the angle.

(3) During friction, the greater force chain strength corresponds to the less worn particles and the less migrated graphite particles.

\section{Acknowledgments:}

The authors are grateful for financial support from the National Natural Science Foundation of China (Grant No. 51275144). 


\section{References}

[1] Liu, J.P., Sun, K., Zeng, L.F., Wang, J., Xiao, X. P., Liu, J.M., Guo,C.J., Ding, Y.: Microstructure and Properties of Copper-Graphite Composites Fabricated by Spark Plasma Sintering Based on Two-Step Mixing. Metals 10, 1056 (2020)

[2] Zhang, P., Zhang, L., Wei, D.B., Wu, P.F., Cao, J.W., Shijia, C.R., Qu, X.H., Fu, K.X.: Effect of graphite type on the contact plateaus and friction properties of copper-based friction material for high-speed railway train. Wear 432, 202927 (2019)

[3] Jiang, X.F., Song, J.J., Su,Y.F., Hu,L.T.: Novel Design of Copper-Graphite Self-Lubricating Composites for Reliability Improvement Based on 3D Network Structures of Copper Matrix. Tribology Letters 66, 143 (2018)

[4] Varol, T., Canakci, A.: An investigation on wear behavior of Cu-graphite nanocomposites prepared by flake powder metallurgy. Industrial Lubrication and Tribology 69, 8-14 (2017)

[5] Cui, G.J., Ren, J., Lu, Z.X.: The Microstructure and Wear Characteristics of Cu-Fe Matrix Friction Material with Addition of SiC. Tribology Letters 65, 108 (2017)

[6] Ferrer, C., Pascual, M., Busquets, D., Rayon, E.: Tribological study of Fe-Cu-Cr-graphite alloy and cast iron railway brake shoes by pin-on-disc technique. Wear 268, 784-789 (2010)

[7] Zhan, Y.Z., Shi, X.B., Xie, H.F.: Microstructural investigation on antifriction characteristics of self-lubricating copper hybrid composite. Materials Science and Technology 22, 368-374 (2006)

[8] Xu, E.Z., Huang, J.X., Li, Y.C.: Graphite cluster/copper-based powder metallurgy composite for pantograph slider with well-behaved mechanical and wear performance. Powder Technology 34, 551-560 (2019)

[9] Liu, Y.B., Lim, S.C., Ray, S., Rohatgi, P.K.: Friction and wear of aluminium-graphite composites: the smearing process of graphite during sliding. Wear 159, 201-205 (1992)

[10] Rohatgi, P.K., Ray, S., Liu , Y.: Tribological properties of metal matrix-graphite particle composites.International. International Materials Reviews 37, 129-149 (1992)

[11] Gong, R., Zhang, H., Che, H., Zhu, M., Xu, Y.: A microscale mesh numerical method for simulating tribological characteristics of sealing materials. International Journal for Numerical Methods In Engineering 108, 1159-1173 (2016)

[12] Liu, J.G., Wang, G.S., Peng, T.H., Jiang, S.Q.: Numerical Simulation of Solid Particle Erosion in Aluminum Alloy Spool Valve. Mathematical Problems in Engineering 2019, 9465406 (2019)

[13] Qin, W.J., Wang, M., Sun, W., Shipway, P., Li, X.D.: Modeling the effectiveness of oil lubrication in reducing both friction and wear in a fretting contact. Wear 426, 770-777 (2019)

[14] Schulze, V., Hoffmeister, J., Nusskern. P.: Simulation of the Manufacturing Process of Case-Hardened Powder Metallurgical Components: Carburizing Simulation. Advanced Engineering Materials 16, 147-150 (2014)

[15] Xue, Y., Chen, J., Guo, S., Meng, Q., Luo, J.: Finite element simulation and experimental test of the wear behavior for self-lubricating spherical plain bearings. Friction 6, 297-306 (2018)

[16] Wang, W., Liu, Y., Zhu, G. Q., Liu, K.: Using FEM-DEM coupling method to study three-body friction behavior. Wear 318, 114-23 (2014) 
[17] Zhang, B., Liu, S.P., Xia, J., Chen, Y.G., Tang, Y.B.: Investigation of the experiment and simulation on TiH2 powder packing by a novel irregular 3D model. Materials Research Express 8, 026510 (2021)

[18] Xie, T., Chen, K., Zhou, Z.H., Yang, H.P.: Numerical Simulation of the Dynamic Evolution of the Friction Interface of PTFE/45 Steel Friction Pair. Materials Research Express 6, 105338 (2019)

[19] Xie, T., Lan, J.J., and Yang, H.P.: Simulation of effect of counterface roughness on the friction transfer and wear of PTFE sliding against steel. Industrial Lubrication and Tribology 71, 1086-1092 (2019)

[20] Wang, C., Tannant, D.D., Lilly, P.A.: Numerical analysis of the stability of heavily jointed rock slopes using PFC2D. International Journal of Rock Mechanics \& Mining Sciences 40, 415-424 (2003)

[21] Potyondy, D.O., Cundall, P.A.: A bonded-particle model for rock. International Journal of Rock Mechanics \& Mining Sciences 41, 1329-1364 (2004)

[22] Xie, T., Yang, H.P., Zhou, Z.H., Yang, T.T.: Numerical Simulation of the Transfer Process at Tribo-interface of Polymer/Metal. Tribology 34, 140-145 (2014)

[23] Xin, H.L., Sun, Q.C., Liu, J.G., Jin, F.: Evolution of force chains in a granular assembly based on indentation test. Rock and Soil Mechanics 30, 88-92 (2009)

[24] Zhang, W., Zhou, J., Yu, S.W., Zhang. X. J., Liu, K.: Investigation on contact force and force chain of granular matter in biaxial compression. Chinese Journal of Applied Mechanics 35, 530-537 (2018)

[25] Fu, L.L., Zhou, S.H., Tian, Z.Y., Tian, Z.K.: Force chain evolution in granular materials during biaxial compression. Rock and Soil Mechanics 40, 2427-2434 (2019)

[26] Rohatgi, P.K., Ray, S., Liu, Y.: Tribological properties of metal matrix-graphite particle composites. International Materials Reviews 37, 129-149 (1992)

[27] Ma, W.L, Lu, J.J.: Effect of Sliding Speed on Surface Modification andTribological Behavior of Copper-Graphite Composite. Tribology Letters 41, 363-370 (2011) 
Figures

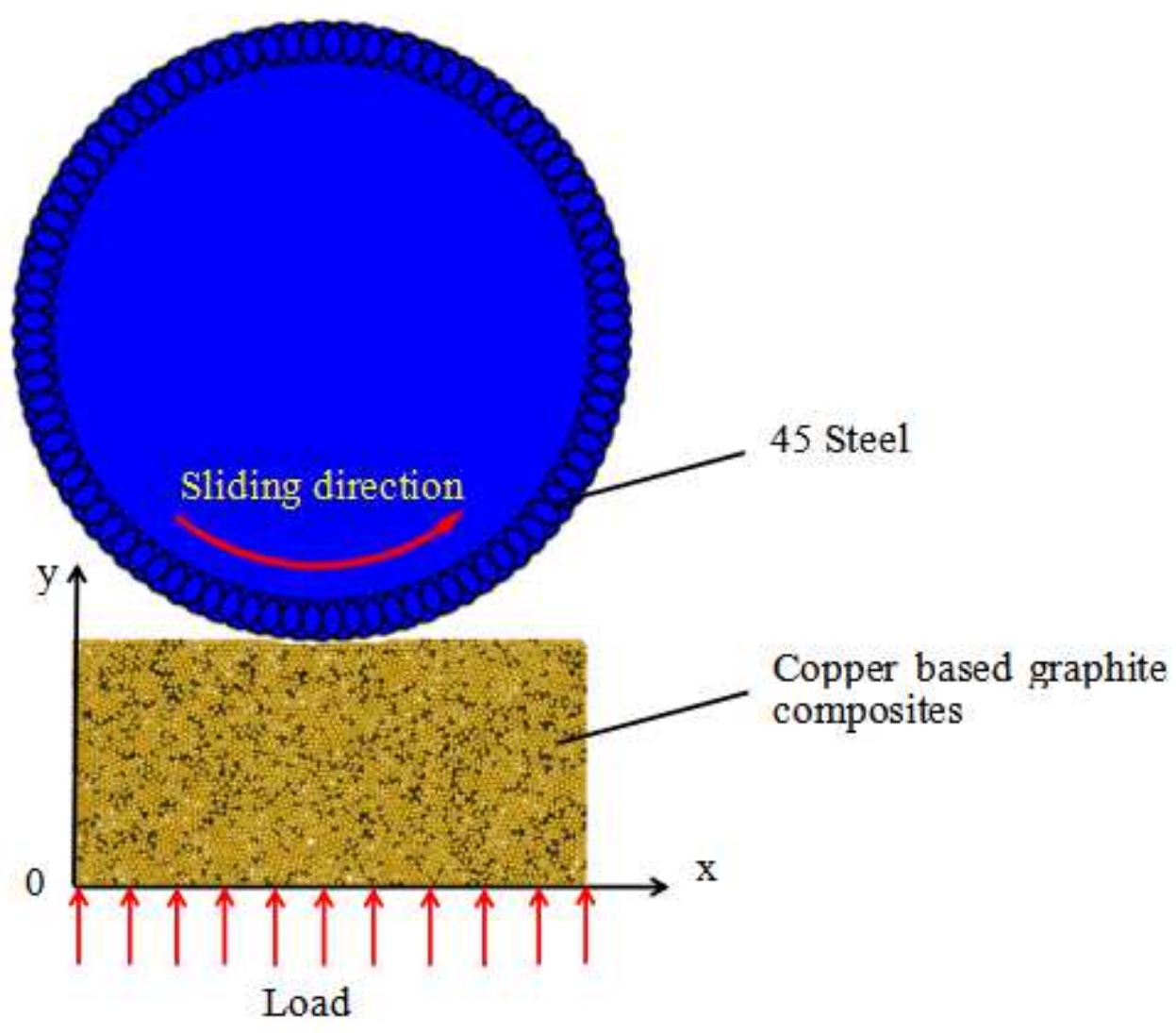

Figure 1

Numerical simulation model of the friction pair 


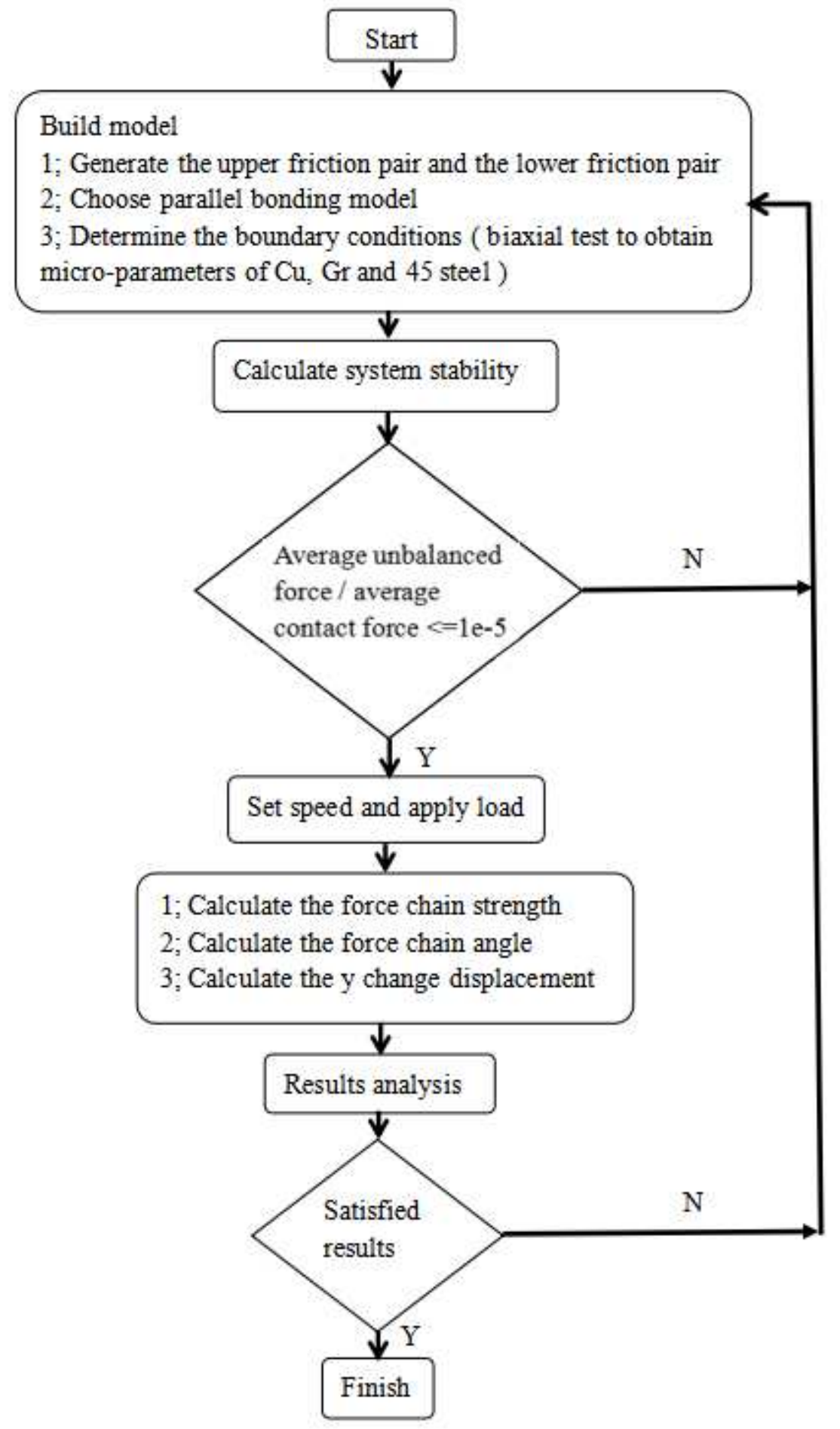

Figure 2

Flow chart of the simulation process by PFC2D 


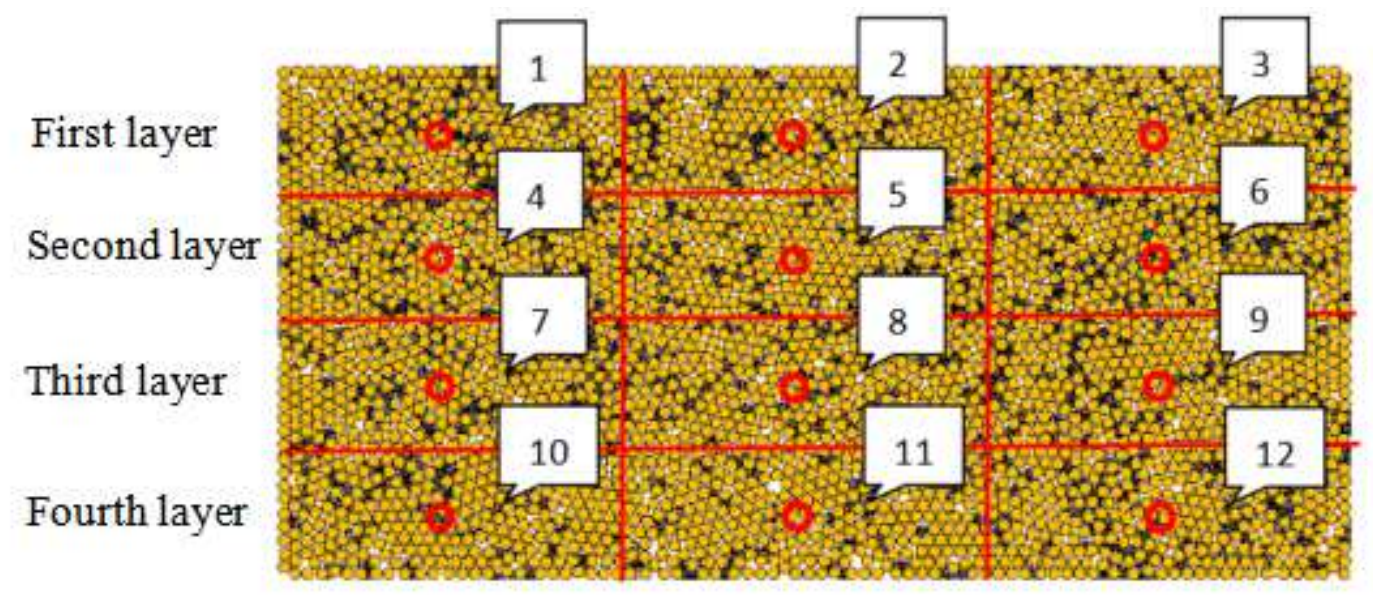

Figure 3

Selected target particles

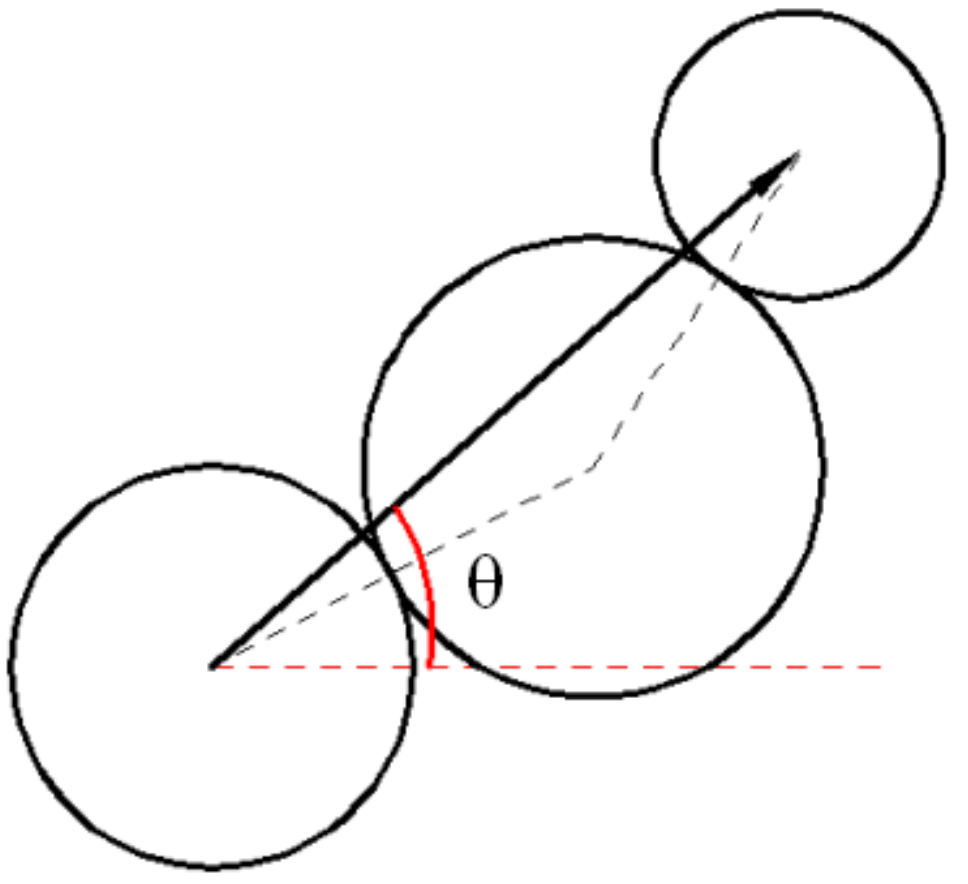

Figure 4

Force chain direction 

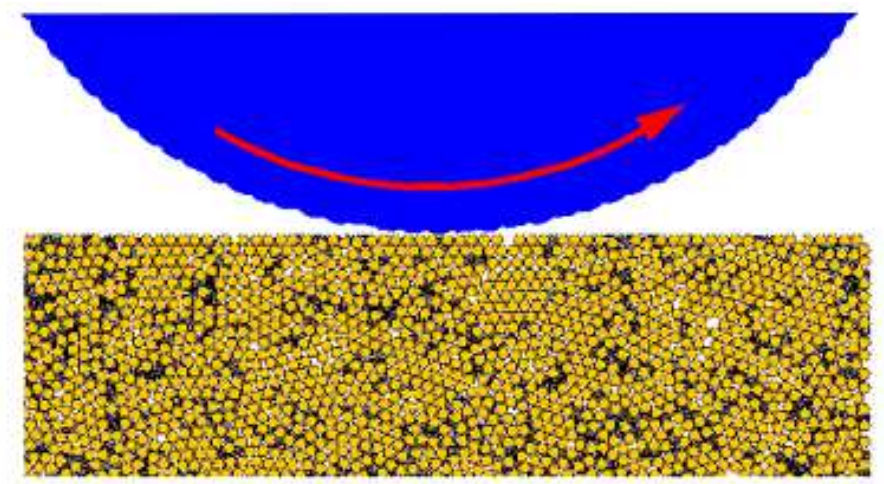

(a)

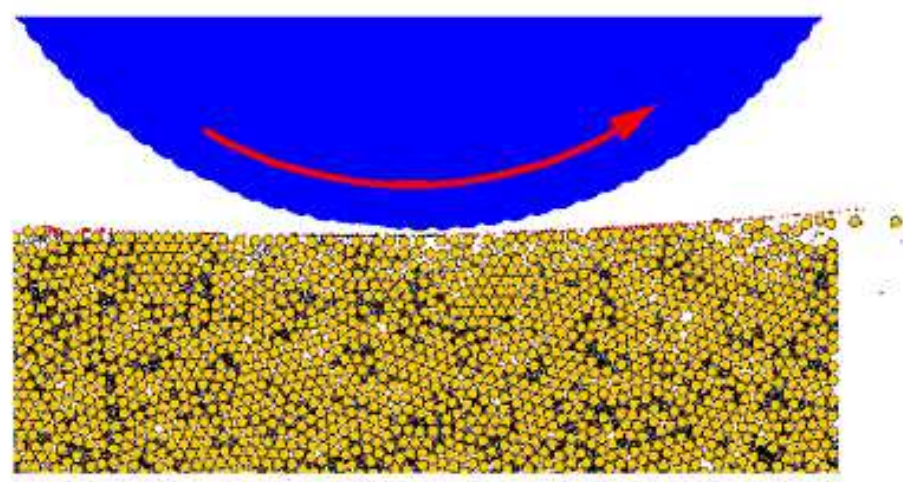

(b)

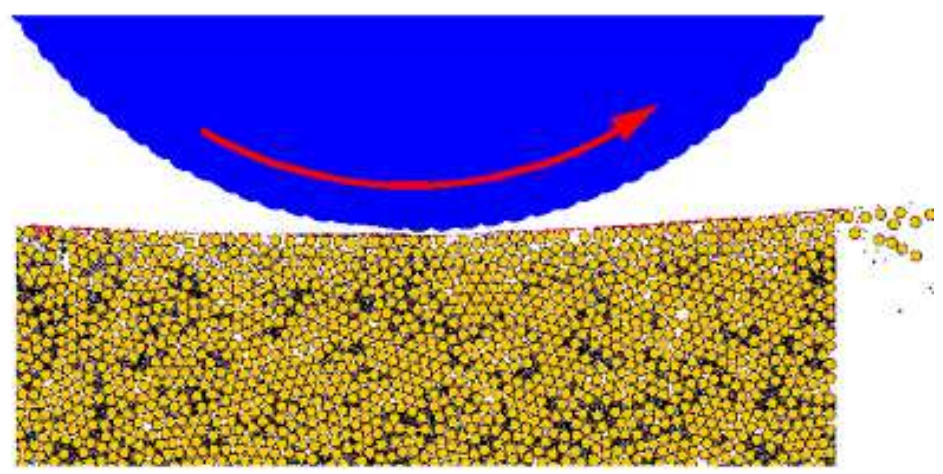

(c)

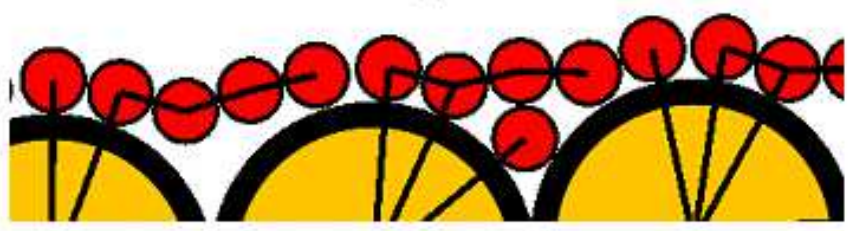

(d)

Figure 5

Particle migration and wear process at different time step, (a) time step 0; (b) time step 2500000; (c) time step 5000000; (d) Partially enlarged image of the migrated particle layer 


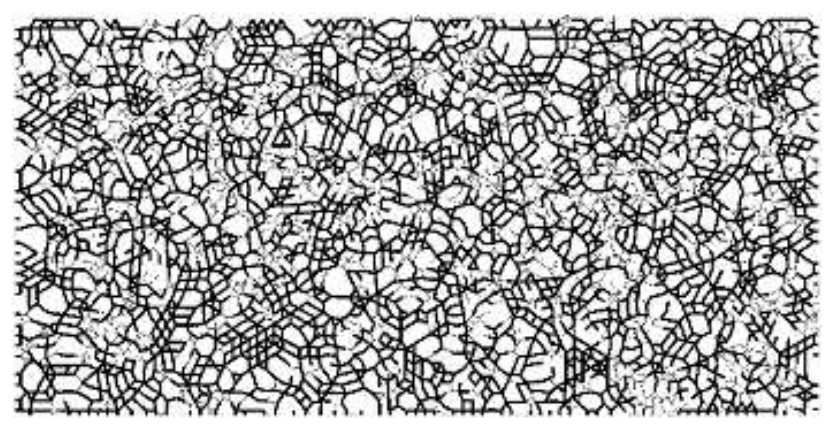

(a)

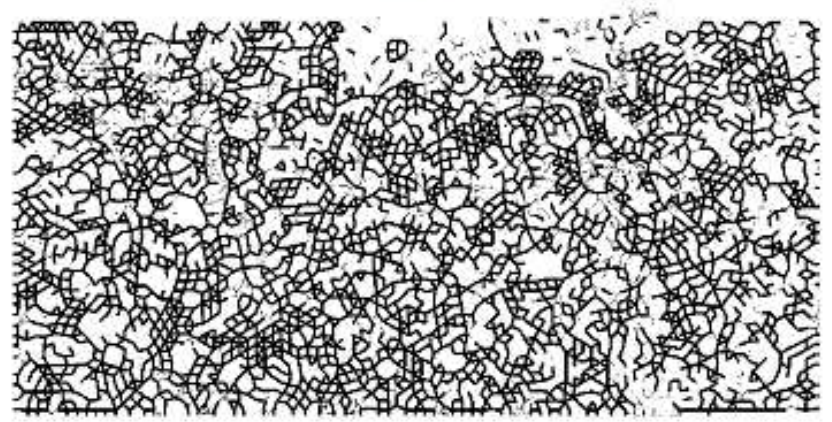

(b)

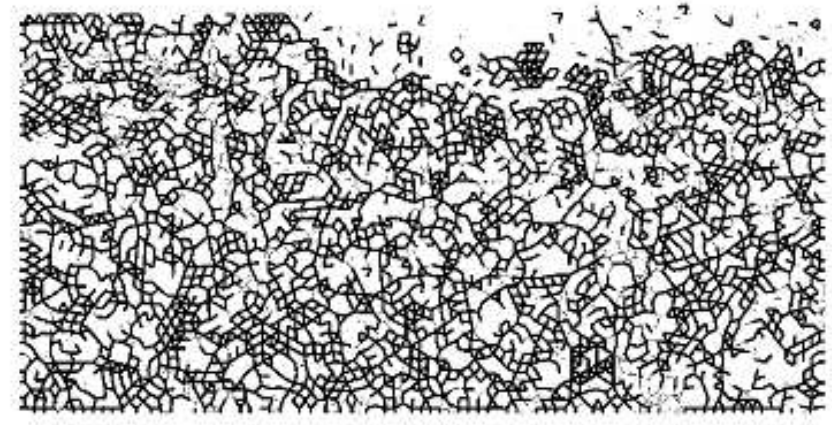

(c)

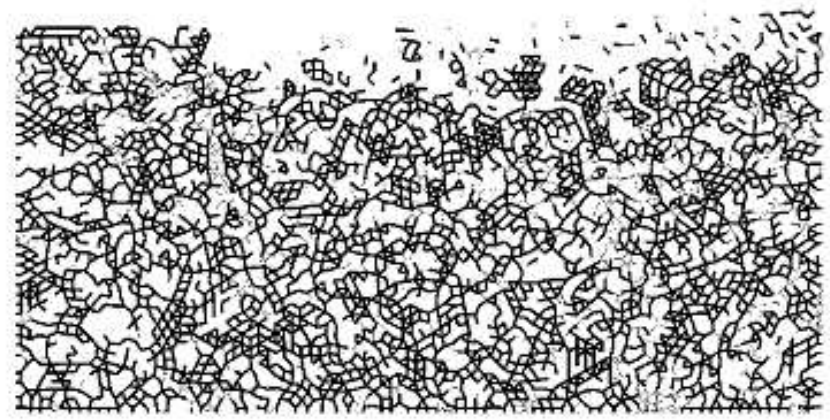

(d)

Figure 6

Macroscopic distribution characteristics of the force chain, (a) time step 0; (b) time step 1500000; (c) time step 30000000; (d ) time step 4500000 


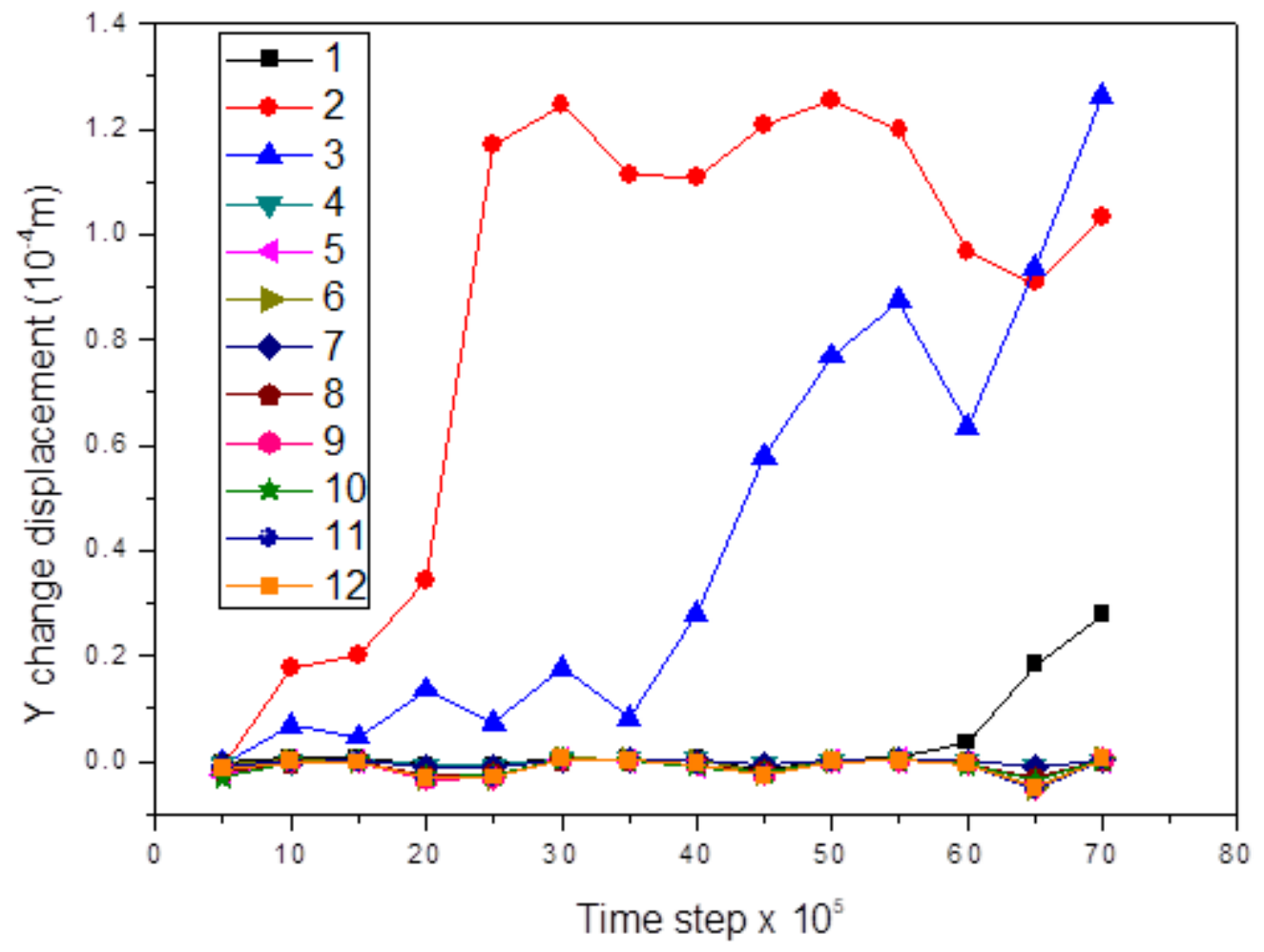

Figure 7

Y migration displacement of the selected graphite particles 


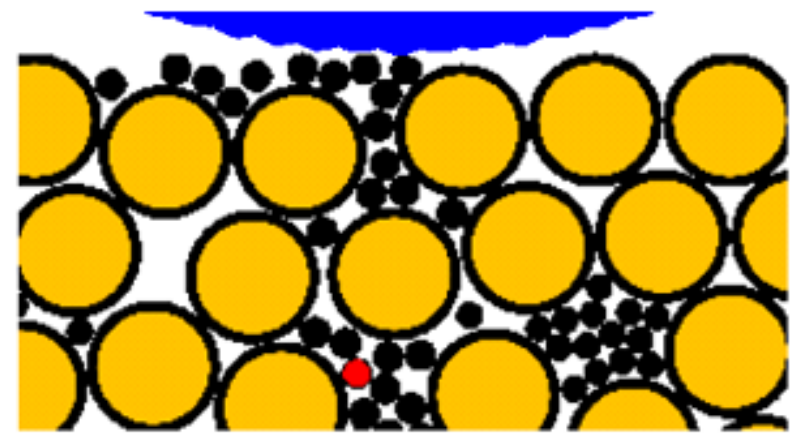

(a)

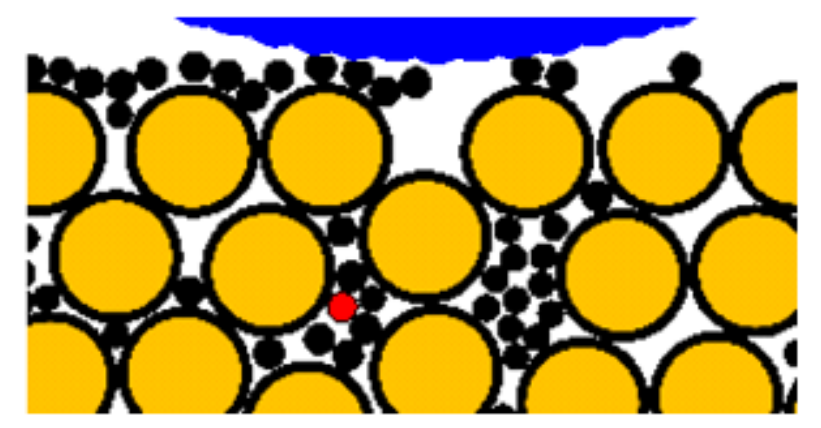

(b)

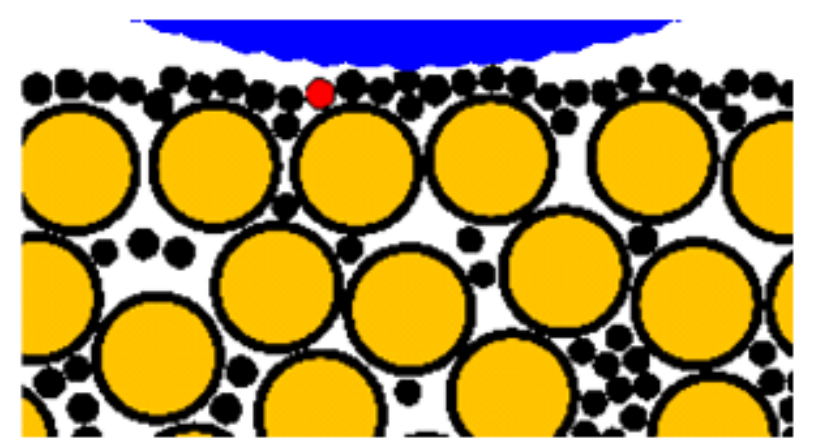

(c)

Figure 8

Graphite particle 2 position state at different time step (the red particle is the target graphite particle 2),

(a) time step 500000; (b) time step 2000000; (c)time step 3500000 


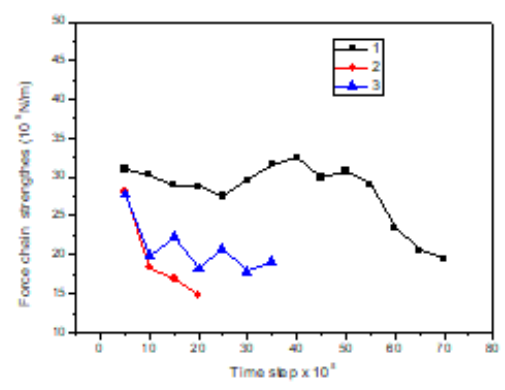

(a)

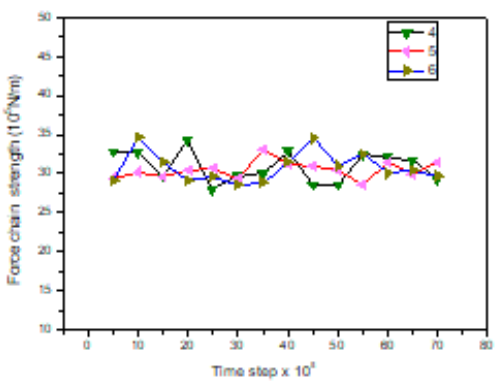

(c)

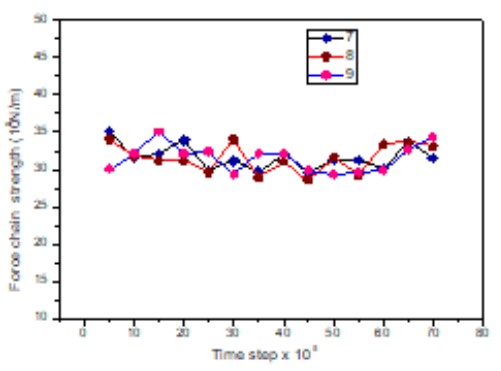

(e)

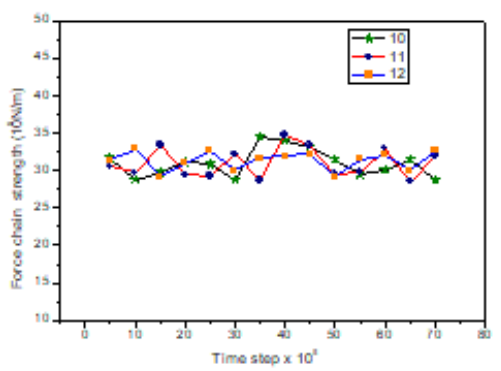

(g)

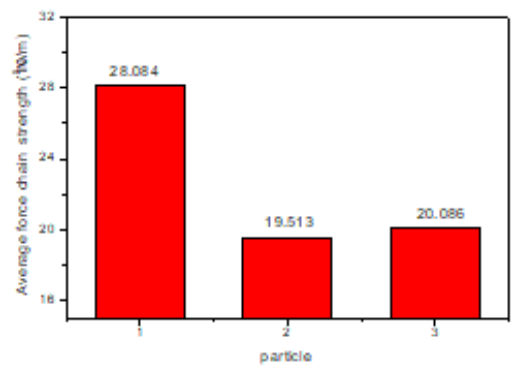

(b)

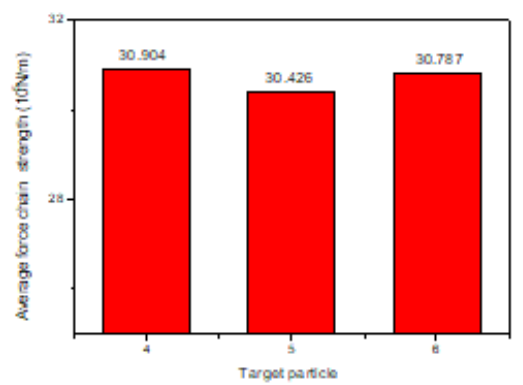

(d)

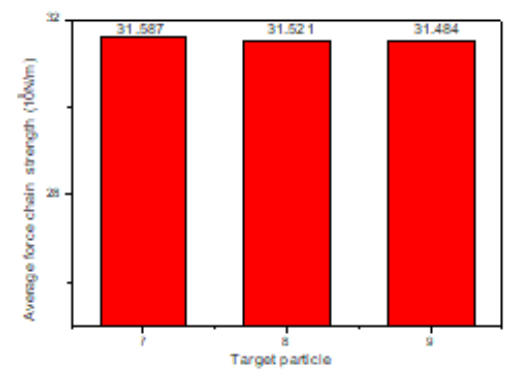

(f)

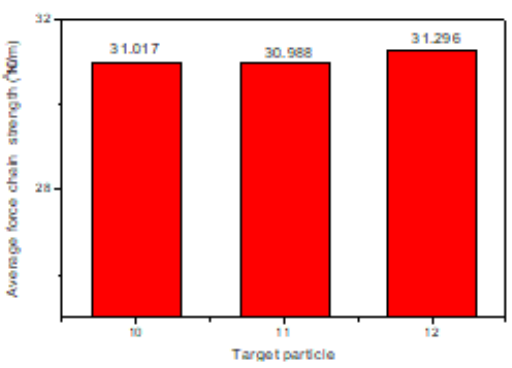

(h)

\section{Figure 9}

Force chain strength at different time step, (a) Graphite particle 1 to 3 force chain strength vs time step; (b) Graphite particle 1 to 3 average force chain strength; (c) Graphite particle 4 to 6 force chain strength vs. time step; (d) Graphite particle 4 to 6 average force chain strength; (e) Graphite particle 7 to 9 force chain strength vs. time step; (f) Graphite particle 7 to 9 average force chain strength; (g) Graphite particle 10 to 12 force chain strength vs. time step; (h) Graphite particle 10 to 12 average force chain strength 


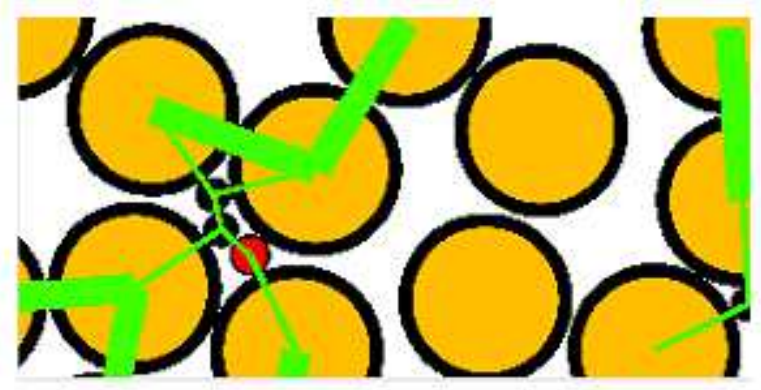

(a)

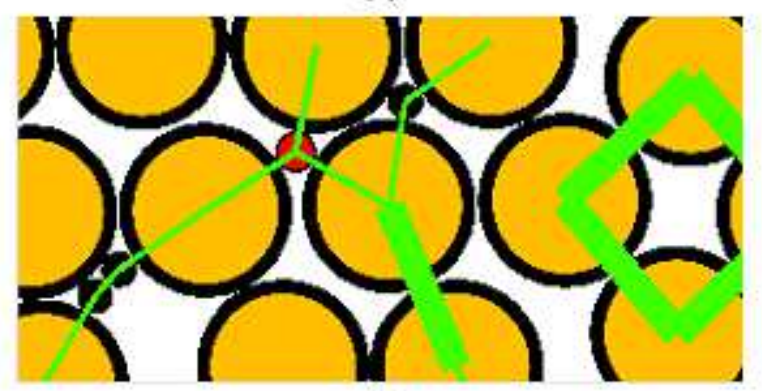

(b)

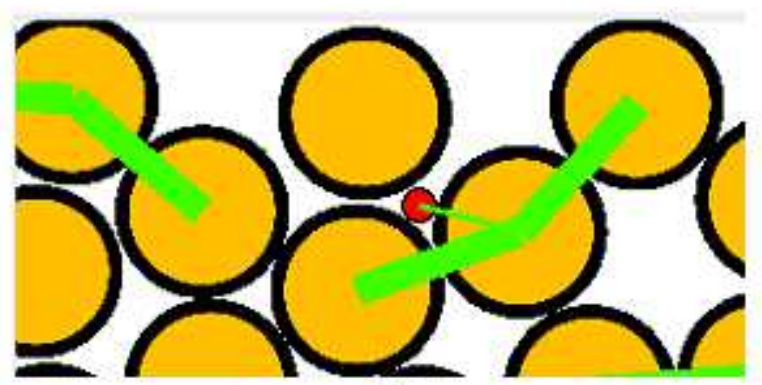

(c)

Figure 10

Graphite particle 3 force chain state at different time step (the red particle is the target graphite particle 3), (a) time step 1000000; (b) time step 2000000; (c) time step 3000000 


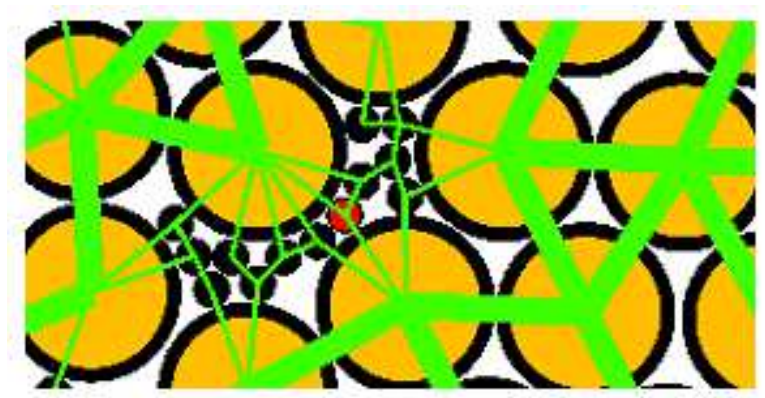

(a)

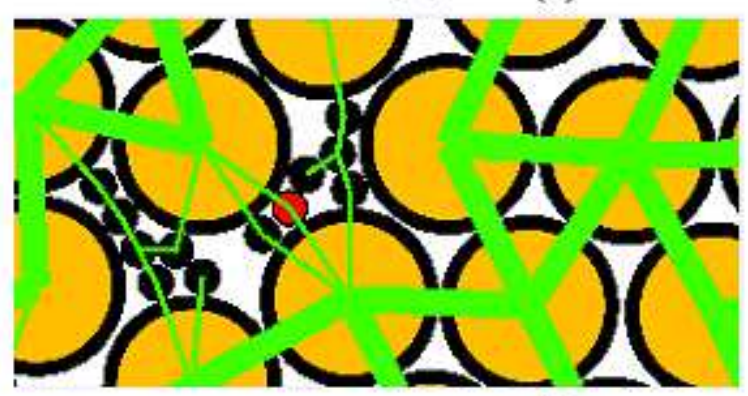

(b)

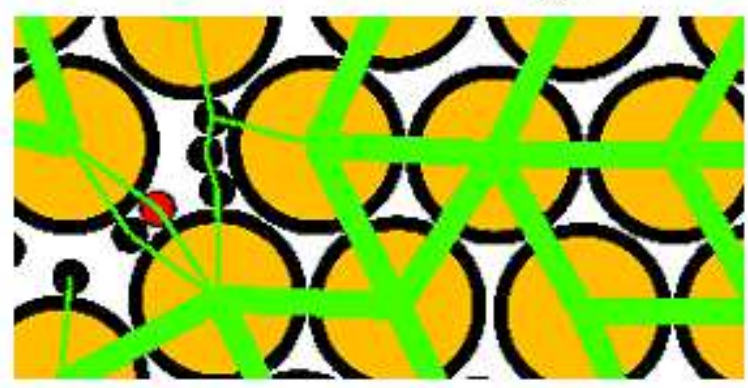

(c)

Figure 11

Graphite particle 5 force chain state at different time step (the red particle is the target graphite particle 5), (a) time step 2000000; (b) time step 4000000; (c)time step 6000000 


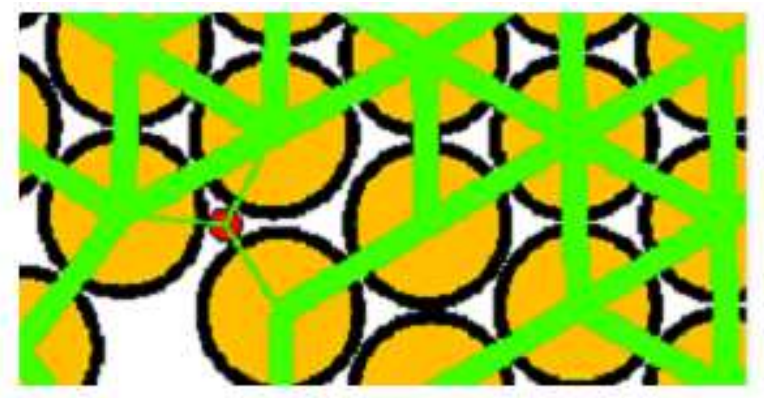

(a)

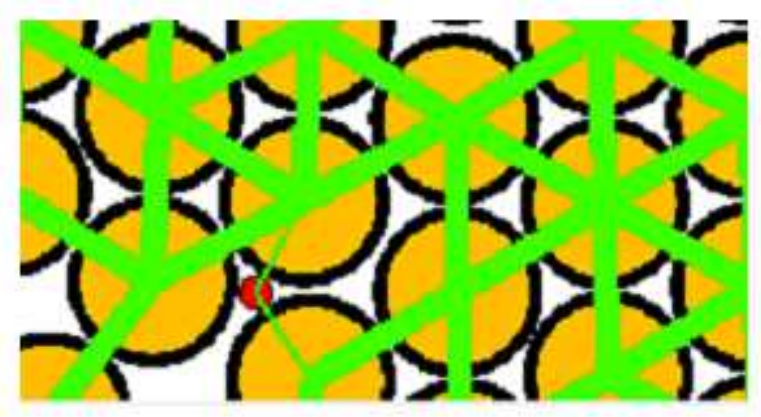

(b)

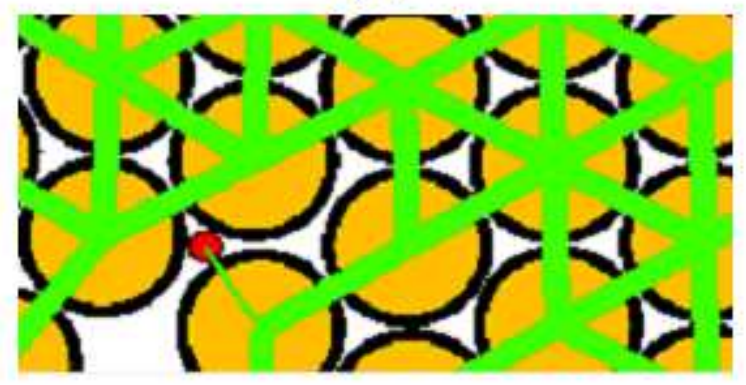

(c)

Figure 12

Graphite particle 8 force chain state at different time step (the red particle is the target graphite particle 8), (a) time step 2000000; (b) time step 4000000; (c)time step 6000000 


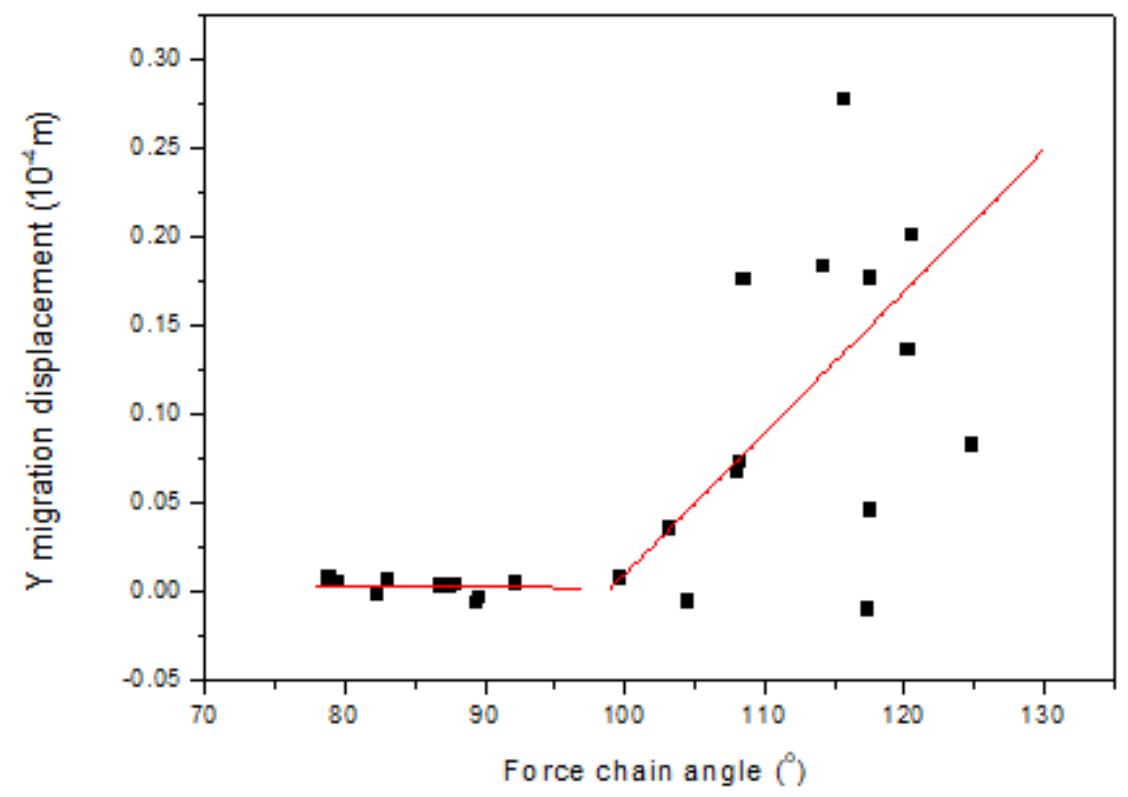

Figure 13

Relations between graphite migration displacement and force chain angle

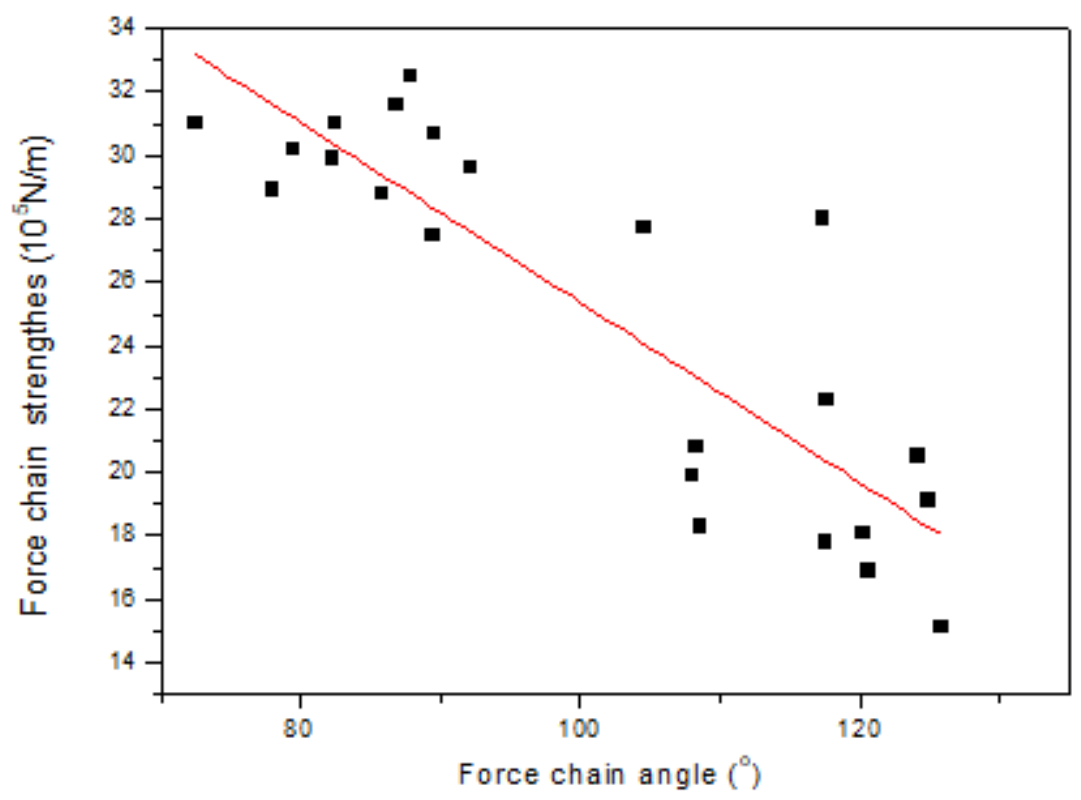

Figure 14

Relations between force chain strength and force chain angle 


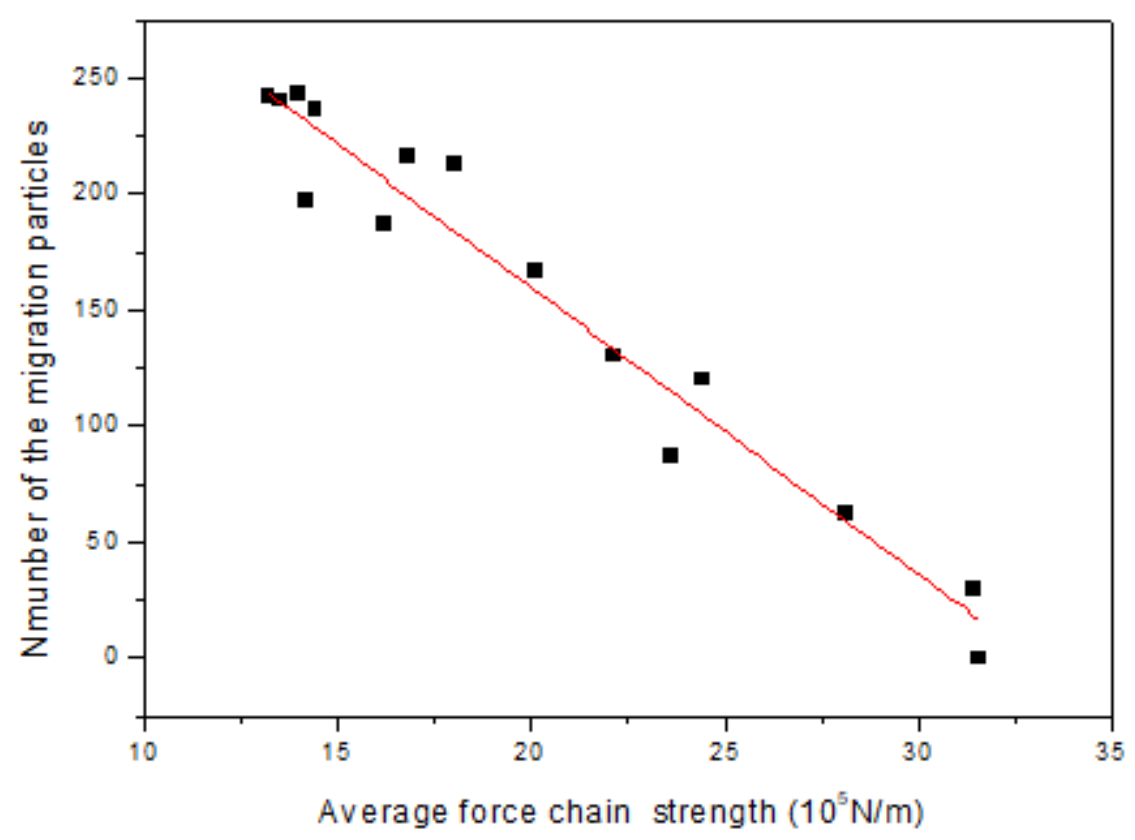

(a)

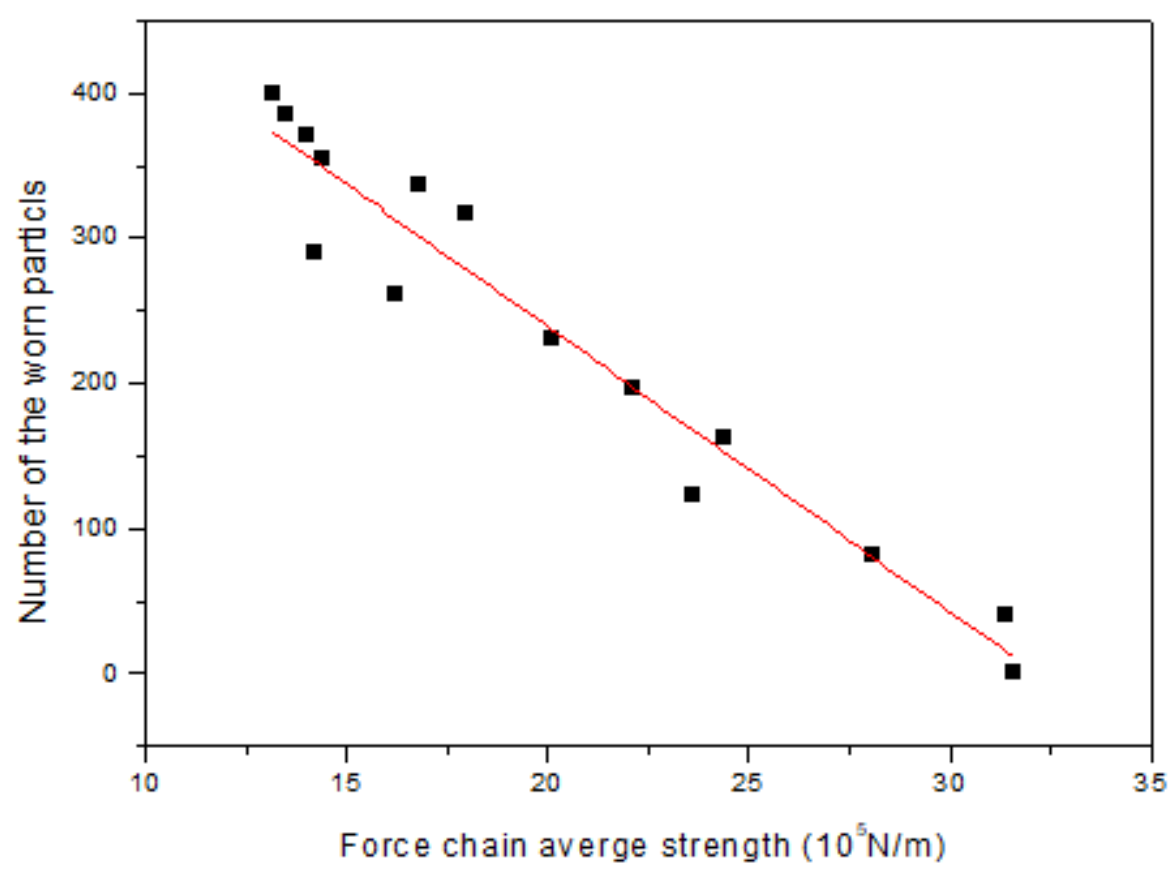

(b)

Figure 15

Relations of the migration particle with average force chain strength (a) and the worn particle with average force chain strength (b) 